BNL-73313-2004

Formal Report

\title{
PROCEEDINGS OF THE 2004 NATIONAL OILHEAT RESEARCH ALLIANCE TECHNOLOGY SYMPOSIUM
}

\author{
Held at the \\ Oilheat Visions Conference (Track 4) \\ Rhode Island Convention Center \\ Providence, Rhode Island \\ August 23-24, 2004
}

Editor

Roger J. McDonald

August 2004

Sponsored by

Building Technologies Program

Office of Energy Efficiency and Renewable Energy

United States Department of Energy

National Oilheat Research Alliance

New England Fuel Institute

Petroleum Marketers Association of America

Energy Resources Division

Energy Sciences and Technology Department

Brookhaven National Laboratory

Brookhaven Science Associates

Upton, New York 11973-5000

Under Contract No. DE-AC02-98CH10886 with the UNITED STATES DEPARTMENT OF ENERGY 


\section{NOTE}

The timeliness of the material in this report requires prompt publication. Therefore, to expedite publication, these papers have been reproduced directly from the author's manuscripts. The conference sponsors, organizing committee, and staff disclaim any and all responsibilities for the contents of individual papers and abstracts.

\section{DISCLAIMER}

This report was prepared as an account of work sponsored by an agency of the United States Government. Neither the United States Government nor any agency thereof, nor any of their employees, nor any of their contractors, subcontractors, or their employees makes any warranty, express or implied, or assumes any legal liability or responsibility for the accuracy, completeness, or usefulness of any information, apparatus, product, or process disclosed, or represents that its use would not infringe privately owned rights. Reference herein to any specific commercial product, process, or service by trade name, trademark, manufacturer, or otherwise, does not necessarily constitute or imply its endorsement, recommendation, or favoring by the United States Government or any agency, contractor or subcontractor thereof. The views and opinions of authors expressed herein do not necessarily state or reflect those of the United States Government or any agency, contractor, or subcontractor thereof. 
Acknowledgements ..................................................................................................... iv

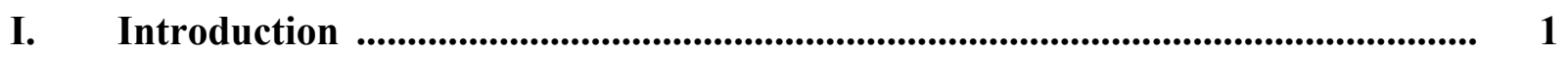

II. Technical Papers Submitted for Publication........................................................... 3

No. 01-04 Development of 2-stage oil fired furnace

Everett James and Mike Sharkozy, Thermo Products LLC .................. 3

No. 02-04 Fuel Oil Viscosity Changes and their Effect on Burner Performance

Victor J. Turk, P.E., R.W. Beckett Corporation ................................... 11

No. 03-04 New York State market demonstration of low sulfur fuel oil

Roger J. McDonald, Brookhaven National Laboratory and

John Batey, P.E., Energy Research Center Inc.

No. 04-04 Metal dusting in low-NO ${ }_{x}$ recirculation burners for fuel oil K. Lucka a , H. Ackermann ${ }^{a}$, H. Koehne ${ }^{a}$, L. Lucks ${ }^{b}$, 'Oel-Wärme-Institut gGmbH, Kaiserstr. 100, 52134 Herzogenrath (Germany) ${ }^{b}$ Institut für wirtschaftliche Oelheizung e.V., Süderstr. 73a, 20097 Hamburg ......... 31

No. 05-04 Large population remote diagnostic and oil usage system

Richard Simons, Honeywell

No. 06-04 Evaluation of soybean heating oil blends for use in residential applications

Nicholas W. Vanlaningham, Harry G. Gibson, Bradley G. Kaufman

Purdue University, Agricultural and Biological Engineering 


\section{ACKNOWLEDGMENTS}

The 2004 National Oilheat Research Alliance Technology Symposium required the dedicated effort of many people to make it successful. The editor of this report would like first to thank the authors for their efforts and splendid cooperation in submitting papers promptly. The BNL staff also wishes to recognize the contributions to our work by our U.S. DOE program manager, Arun Vohra, and thank him for his leadership. The editor also greatly acknowledges the hard work and effort required by the entire BNL program staff to make this meeting a success. Most of all the staff at BNL wishes to thank all of our 2004 National Oilheat Research Alliance Technology Symposium sponsors and participants for their active participation. 


\section{INTRODUCTION}

This meeting is the seventeenth oilheat industry technology meeting held since 1984 and the forth since the National Oilheat Research Alliance was formed. This year's symposium is a very important part of the effort in technology transfer, which is supported by the Oilheat Research Program under the United States Department of Energy, Building Technologies Program within the Office of Energy Efficiency and Renewable Energy. The foremost reason for the conference is to provide a platform for the exchange of information and perspectives among international researchers, engineers, manufacturers, service technicians, and marketers of oil-fired spaceconditioning equipment. The conference provides a conduit by which information and ideas can be exchanged to examine present technologies, as well as helping to develop the future course for oil heating advancement. These conferences also serve as a stage for unifying government representatives, researchers, fuel oil marketers, and other members of the oil-heat industry in addressing technology advancements in this important energy use sector. The specific objectives of the conference are to:

o Identify and evaluate the current state-of-the-art and recommend new initiatives for higher efficiency, a cleaner environment, and to satisfy consumer needs costeffectively, reliably, and safely;

o Foster cooperative interactions among federal and industrial representatives for the common goal of sustained economic growth and energy security via energy conservation.

The 2004 National Oilheat Research Alliance Technology Symposium is sponsored by the United States Department of Energy (DOE), Building Technologies Program within the Office of Energy Efficiency and Renewable Energy (EERE-BT), the National Oilheat Research Alliance (NORA), the New England Fuel Institute (NEFI), Brookhaven National Laboratory (BNL) and the Petroleum Marketers Association of America (PMAA). BNL is proud to acknowledge all of our sponsors; with their help and support this has correctly become an oilheat industry meeting. It is quite gratifying to see an industry come together to help support an activity like the technology symposium, for the benefit of the industry as a whole.

Raymond Albrecht, the 2004 Master of Ceremonies provided introductory remarks. Mr. Albrecht is a program manager for the New York State Energy Research and Development Authority (NYSERDA) in heating and cooling technology and also a member of the NORA Board of Directors and also the Board of Directors of the National Oilheat Research Institute (NORI). Ray Albrecht welcomed the assembly on behalf of all of our sponsors and set the tone for the meeting. He emphasized the continued commitment by NYSERDA, NORA, NORI, DOE and BNL to advancing oil heat technology and effecting technology transfer to the private sector.

Sixteen technical presentations were made during the two-day program, all related to oil-heat technology and equipment, these covered a range of research, developmental, and demonstration activities being conducted within the United States and Europe, including:

- Development of a new high efficiency oil-fired condensing furnace (NORA R\&D grant)

- Oil-fired condensing boilers

- Development of two-stage oil fired furnace 
- Improving fuel oil quality in the oilheat industry

- Upcoming environmental regulations that may impact the oilheat industry

- Fuel oil viscosity changes and their effect on burner performance

- New York State market demonstration of low sulfur fuel oil

- Quality of heating oil - developments of technology and standards in Europe

- Metal dusting in low-nox recirculation burners for fuel oil

- Large population remote diagnostic and oil usage system

- Smart control technology and maximizing service intervals

- Tests of a modulating oil burner

- Biofuel blend properties and future work at Brookhaven National Laboratory

- Overview of oilheat dealer activities in bio-heating fuel marketing

- European experience with bio-diesel and bio-heating fuels

- Evaluation of soybean heating oil blends for use in residential applications

This year formal papers were optional based on numerous requests from individuals that were constrained by time and budget availability. As a result only six papers were submitted for publication in this proceedings report. 


\section{Technical Presentations}

Paper No. 01-04

\section{Development of two-stage oil fired furnace}

Everett James and Mike Sharkozy

Thermo Products LLC

PO Box 217

North Judson, IN 46366

Phone: (574) 896-2133

Fax: (574) 896-5301

E-mail: ejames@thermopride.com

E-mail: msharkozy@thermopride.com

Internet: www.thermopride.com 


\section{Development of Two-stage Oil Fired Furnace}

Thermo Products has been manufacturing oil fired heating equipment to serve the residential market for in excess of 50 years. Thermo Products has successfully maintained a reputation of providing high quality, reliable equipment to the installing segment for their customers.

The residential oil forced air furnace market has seen continual decrease in the number of units installed on an annual basis. This reduction can be attributed to a number of factors including the concern (at the consumer level) of reliable fuel source, operating efficiencies, fuel cost and cleanliness of operation. The chief competitive fuels of natural and liquefied petroleum gases have made inroads into the oil market due to its ability to provide variable inputs, increased operating efficiencies and perceived operating comfort options. Enhanced comfort options in particular were identified as a possible product improvement for the forced air oil fired furnace market to improve upon with secondary gains in operating efficiencies both thermal and electrical. Staged firing and Variable Speed motors (ECM electrically commutated motors - DC variable speed) have allowed the gas products to improve comfort levels while operating at higher electrical efficiencies during the heating mode as well as in the air conditioning mode. The gas market offers, and is experiencing a growing demand for, 2-stage operation at the midefficiency levels. Although the demand is not efficiency driven, the market is demanding the 2stage option for the increased comfort levels generated.

Currently, Thermo Products has identified a need within the oil forced air-heating market for a 2Stage fired oil furnace. Incorporating existing 2-Stage burner technology and integrating variable blower motor designs to provide enhanced oil fired furnace comfort and operating at greater efficiency levels is the prime objective of the project. In addition to the heating mode, the variable speed technology of the circulating air blower would enhance the overall system efficiency of an Air Conditioning Condenser, installed in conjunction with this furnace, by as much a $1+$ SEER point.

The oil market has not had the ability to offer the 2-stage option in either the oil forced air or hydronic market.

The following discussion will detail specifically the definition of the problem foreseen and steps taken to address each issue of the project.

Currently, domestic burner product availability does not provide for 2-stage burner option that incorporates stepped input with matching step combustion air control. Also, existing control systems, while available for the gas fuel option, does not exist for two-stage oil fired control integration.

This project has been broken down into three major tasks. Task one is to identify and apply a 2stage oil burner to an existing furnace model capable of operating at the residential level while meeting economic guidelines. Task two is to define, program and apply Variable Speed motor technology to the product supporting the stepped level of heating inputs and integrating desired cooling capabilities. The third task is to develop a control system that will safely control 2 -stage oil fired heating operation while taking advantage of the Variable Speed motor technology. 
The project team identified the Riello R40 G5IR burner as the initial design for application. The standard G5IR burner is currently manufactured for use in the European community operating at 230VAC 50HZ. There is no current domestic burner configuration used in the states so all initial burner application operation is provided through the use of a Visicomm Frequency Converter. Work with Riello has subsequently developed a burner for domestic use. Application evaluation consisted of proper burner insertion, operating temperature limits and optimized stepped firing levels.

This available burner technology allows for step fired fuel supply operating at approximately 200 PSI on high fire and 130 PSI operation at lo-fire. The burner also integrates control of the combustion air simultaneous with the two firing rates.

Initial product selection was to develop around a .75gph input highboy oil furnace due to the highest heating capacity SKU being sold. Initial burner application results look favorable with performance results as follows:

$\begin{array}{lccllll} & \text { Firing rate } & \text { Pump pressure } & \mathrm{O}_{2} & \mathrm{CO}_{2} & \mathrm{CO} & \text { Gross Stack }{ }^{\circ} \mathrm{F} \\ \text { Low Fire } & 89,870 \mathrm{btu} / \mathrm{hr} & 140 \mathrm{psi} & 3.6 \% & 13.0 \% & 0 \mathrm{ppm} & 417 \\ \text { High Fire } & 108,800 \mathrm{btu} / \mathrm{hr} & 200 \mathrm{psi} & 3.0 \% & 13.4 \% & 1 \mathrm{ppm} & 492\end{array}$

DOE Steady State operation (low fire) $86.8 \%$ AFUE 2-Stage $85.9 \%-86.7 \%$

Specific burner tube insertion length and domestic voltage and frequency requirements had been identified and incorporated into the final burner specification with Riello.

The second step of the project was to apply current available Variable Speed motors to the product matching desired air flow to the defined 2-stage heat inputs insuring proper heat rises and air flow across the heat exchangers. Variable Speed motor technology application was specified to match variable heat rises of $65^{\circ} \mathrm{F}$ to $80^{\circ} \mathrm{F}$ in $5{ }^{\circ} \mathrm{F}$ increments at the 2 different firing rates. Cooling capacity performance levels support 800 to $1400 \mathrm{cfm}$.

The third step of the project was to develop an integrated control system that would provide for easy 2-stage oil fired burner operation while control the circulating fan at the variable flows needed. Control system functionality focused on an integrated electronic fan control combining burner and all blower control functions. The control provides for 120VAC outputs for blower, auxiliary outputs for humidifier and electronic air cleaner hook-ups, dedicated contacts for 2stage burner operation and $24 \mathrm{VAC}$ outputs for compressor contactor. Additional control features designed into the control consisted of (Fig 1):

- Electronic Fan Control

- 2-Stage Heat - Controlled by Time (W2 only) or Temp. (W1 \& W2)

- Selectable Fan ON Delay timing of - 30, 60, 120, $240 \mathrm{sec}$.

- Selectable Fan OFF Delay timing of - 2, 4, 6, 8 min

- Dehumidification Fan Speed Option - Dehum,

- Electronic Air Cleaner and Humidifier integrated contact points - EAC, Hum 

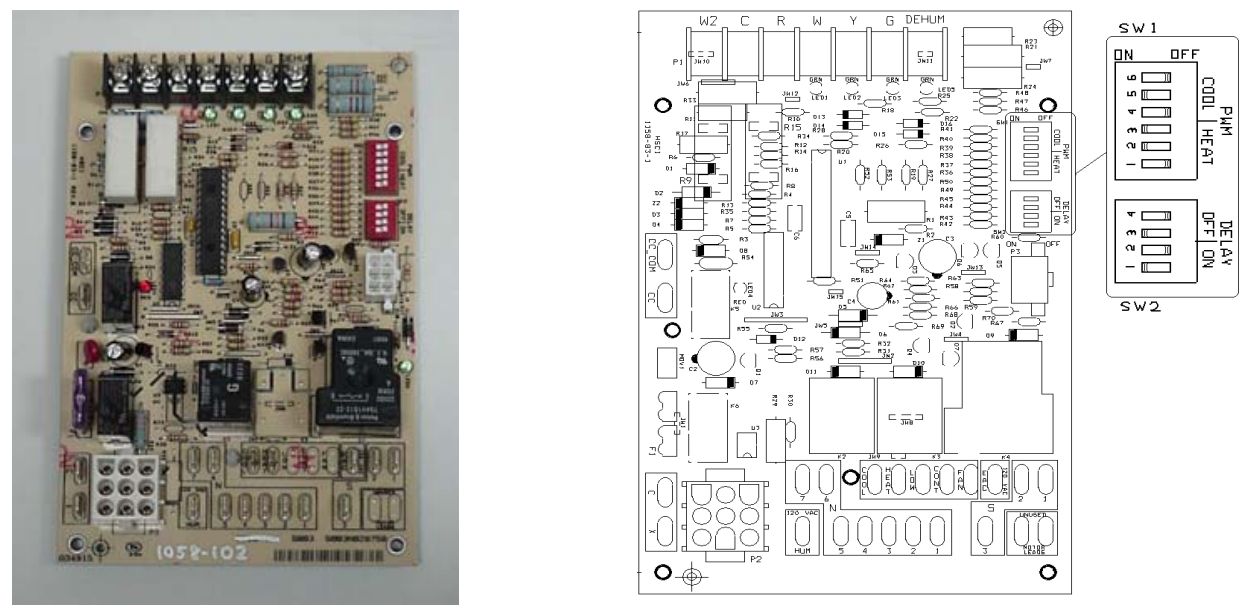

Figure 1

Final product performance numbers has resulted in improved Annual Fuel Utilization Efficiency, improved electrical operating efficiency and enhanced overall heating comfort Table 1. Burner performance has maintain very good combustion levels at both high and low firing rates due to the adjustable air setting available to match the two firing rate inputs controlled through dual solenoid valves Figure 2. While the combustion efficiency of domestic burners approach that of the Riello burner, the noted performance gain has to do with the automatic air shutters on the burner. The advantage of the adjustable air shutter allow for maximizing $\mathrm{CO} 2$ levels for each firing rate but more importantly, at the termination of a call for heat, the air shutters will close off minimizing the off cycle draft loss of the furnace. This reduced draft loss can account for AFUE increases in the magnitude of $2-3$ percentage points.

AFUE tests prescribe operating a 2-stage burner at Low fire and measuring the performance, then operating at High fire and recording performance. The AFUE 2-stage algorithm calculates low fire operating time and efficiency to that of high fire operating time and efficiency and generates an overall performance number. AFUE operating differences between low fire and high fire was recorded at $1.5 \%$ while the net overall impact to system number only reduced the low fire performance number by $.02 \%$.

Table 1

\begin{tabular}{|c|c|c|c|c|c|c|}
\hline & \multicolumn{6}{|c|}{ Final Unit Test Results } \\
\hline & \multicolumn{4}{|c|}{ Test Conditions } & \multicolumn{2}{|l|}{ Test Results } \\
\hline \multirow[b]{2}{*}{ High Fire } & Input & $\mathrm{CO} 2$ & Stack & Rise & \multirow{4}{*}{$\begin{array}{l}\text { Part-Load Efficiency at Reduced Input Rate } \\
\text { Part-Load Efficiency at Maximum Input Rate } \\
\text { Heating Seasonal Efficiency } \\
\text { Annual Fuel Utilization Efficiency } \\
\text { Weighted Average Steady-State Efficiency }\end{array}$} & AFUE \\
\hline & 106,920 & $13.90 \%$ & $464^{\circ}$ & $72^{\circ}$ & & 85.56 \\
\hline \multirow[t]{2}{*}{ Low Fire } & 88,010 & $13.30 \%$ & $440^{\circ}$ & $75^{\circ}$ & & 84.5 \\
\hline & & & & & & $\begin{array}{l}85.54 \\
85.54 \\
84.98\end{array}$ \\
\hline
\end{tabular}




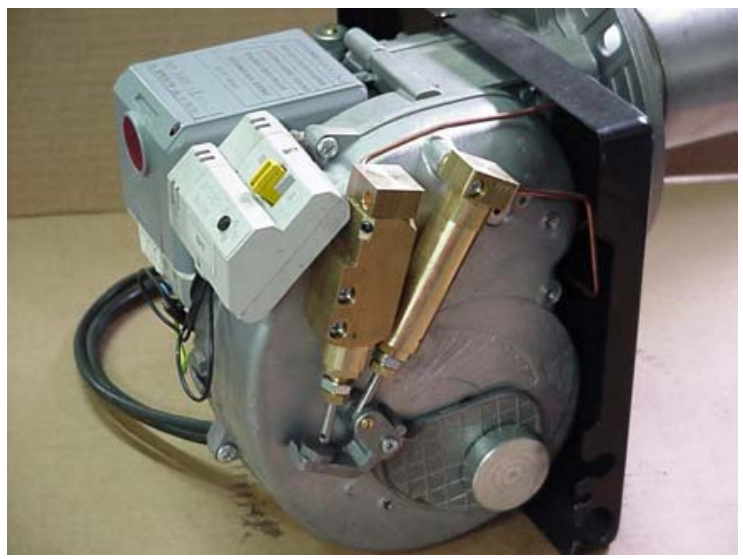

Dual Air Shutter Pistons Provide Improved Air Control at Both Firing Rates

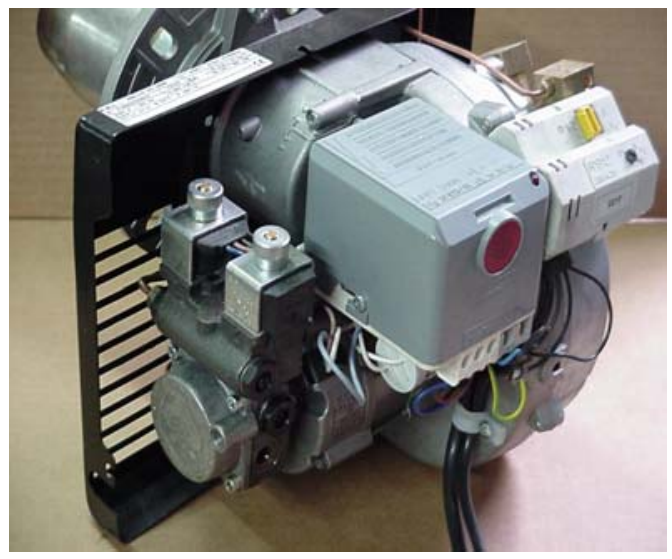

Dual Solenoids control High and Low Fire Operation

Figure 2

Variable Speed motor capabilities delivered desired fan performance while improving electrical operating efficiencies particularly at the lower air speeds needed for heating and low tonnage cooling requirements. Chart 1 is a comparison of the conventional PSC (permanent split capacitor) motor currently being offered on this product with the Variable Speed motor applied and programmed for this 2-stage furnace.

The PSC motor performance curves operate at a flat level between $2.5 \mathrm{cfm} /$ watt to $3.0 \mathrm{cfm} / \mathrm{watt}$ depending on airflow demands. Increased operating efficiency of the Variable Speed motor at the lower airflow levels and static pressures of .2"sp result in gains from $2.7 \mathrm{cfm} /$ watt to 7.5 $\mathrm{cfm} /$ watt at $900 \mathrm{cfm}$ levels. Typical heating and low cooling load requirements. As the demand increased on the circulating fan, the operating efficiency gains of the Variable Speed motor is less dramatic as noted in the comparison of the performance at $1600 \mathrm{cfm}$ levels seeing a modest gain of $2.5 \mathrm{cfm} /$ watt to $2.8 \mathrm{cfm} /$ watt at $.5 \% \mathrm{sp}$.

Final project activities include third party agency approval presenting new burner and control system technology for listing. The Quality Control department, in conjunction with Design Engineering has established a quality strategy addressing the new components reliability plans and production product evaluation. 
ECM vs. PSC - CFM/Watt

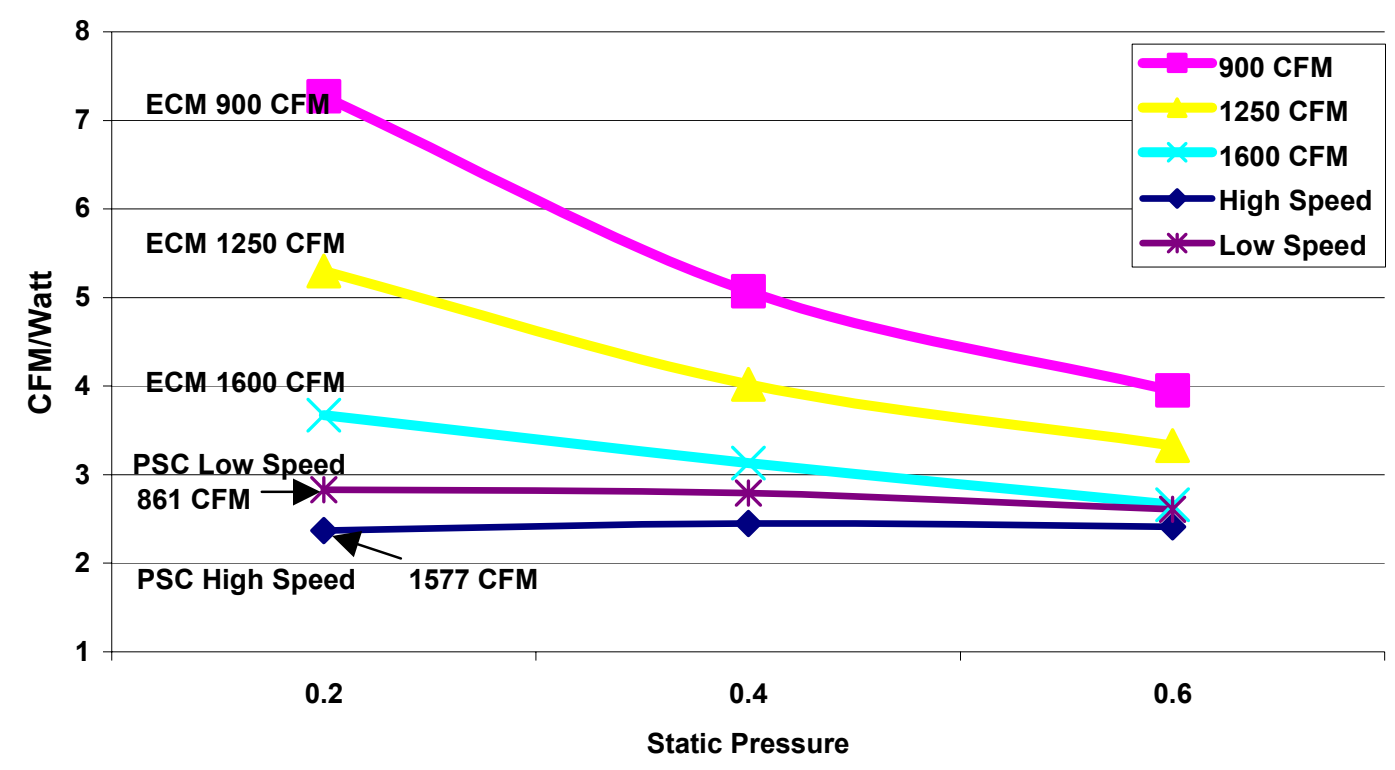

Summary

$130,000+$ oil furnaces are sold annually within the US oil market. Current oil furnace offerings provides for only single stage operation. Although Thermo Products feels the comfort levels delivered in current model exceed that of alternative fuels, the operating level of 2-stage firing would improve the comfort level delivered to the end user, particularly during the lower demand seasons of the fall and spring.

Although 2-stage furnace efficiency levels have not shown dramatic increases when run under current DOE Seasonal Efficiency Test Protocol, the application of the ECM motor technology will result in improved electrical consumption against existing PSC motor operation. This would provide incentive for the energy conscious consumer to seriously look at product offering like this.

Market demand, efficiency rebate programs, environmental concerns and increasing fuel costs generate requirements for more efficient products. The greatest benefit of this product is the ability to provide improved comfort levels of operation as a result of 2-stage combustion technology. This project has the support of NORA's initiative of building an R\&D program for development of advanced oil fired heating equipment thereby enhancing perceptions of the oil market.

It is the position of Thermo Products that the current oil market is in need of technological options that will enhance the comfort delivered to the consumer. The development and introduction of a 2-stage oil furnace with variable speed motor capability will allow the oil marketer to offer a competitive option to his potential residential customer. 


\title{
Paper No. 02-04
}

\section{Fuel oil viscosity changes and their effect on burner performance}

\author{
Victor J. Turk, P.E., Director of Quality \\ R.W. Beckett Corp. \\ P.O. Box 1289 \\ Elyria Ohio 44036 \\ Phone: 440 353-6280 \\ Fax: 440 353-6080 \\ E-mail: vturk@beckettcorp.com \\ Internet: www.beckettcorp.com
}




\section{Fuel Oil Viscosity Changes and their Effect on Burner Performance}

Victor J. Turk, P.E. - R.W. Beckett Corp.

\section{Abstract:}

An increase to the viscosity range limits in ASTM D396, the national fuel oil standard, has been proposed to make the fuel oil viscosity range common with the diesel fuel viscosity range. Since the two products have common base stocks, this change could have a positive effect on the commerce of these fuels, particularly on the size of the pool of these base stocks and the flexibility in manufacturing. Viscosity has a direct effect on fuel flow through the simplex nozzles common in pressure atomizing burners, which are the predominant style of burner in use in North America. This paper evaluates the historical viscosity variation in the national fuel supply, the effects of fuel viscosity on flow rate and combustion performance (at a constant burner air adjustment), and considers the pros and cons of changes in the viscosity range from the perspective of burner performance, service practice and emissions.

\section{Introduction}

With the current environmental pressures to reduce fuel sulfur content, users and producers alike are concerned with the economical production and distribution of heating and diesel fuel oils - middle distillate petroleum fuels. Producers are trying to simplify their production, storage and distribution streams, standardize products, accommodate new (and changing) product requirements and balance the significant investments in processes and equipment to achieve ultra-low sulfur levels. Users are working to understand new product characteristics and limitations and to secure products that meet their needs, are competitively priced and readily available.

A part of this transition is a proposal before ASTM International, the custodian for the national fuel oil standard, ASTM D396, to change the viscosity limits of this standard to match those of the national diesel fuel standard, ASTM D975. This involves increasing the upper viscosity limit from $3.4 \mathrm{cSt}\left(\mathrm{mm}^{2} / \mathrm{s}\right)$ to $4.1 \mathrm{cSt}$. The lower viscosity limit is $1.9 \mathrm{cSt}$ for both products. In question are the direct effects on viscosity-controlled properties like nozzle flow rate, and performance parameters related to nozzle flow. Indirect effects include sulfur content, stability and other properties that result from the way intermediate fuel streams are processed and blended to meet heating oil specifications. From a production and distribution standpoint, these interactions with other blend stocks can affect the number of process streams in the refinery, pipeline transportation and terminal storage, and can determine when and where additives are blended to differentiate different products.

\section{Drivers influencing change}

Market - Demand for middle distillate products (diesel fuel, heating oil, jet fuel, kerosene, etc.) has risen steadily for many years, especially in Europe, where automotive diesel has outstripped gasoline. Although gasoline is still the predominant motor fuel in North America, similar trends exist, and the same is true in the Asian-Pacific region. Much of this is due to the greater efficiencies afforded by diesel technology, but environmental regulations also figure into the picture. ${ }^{(1)}$ Highway diesels tend to contribute higher levels of particulate matter and precursors of ground level 
ozone. As the primary world-wide consumers of middle distillate fuels, diesels have received significant attention from regulators seeking to blunt the growing load of pollutants. What happens to the larger portion of the pool of middle distillate fuels is having at least an indirect effect on the sizeable, albeit smaller, portion that serves as heating fuel, even if the regulations do not directly affect it.

Technology - On the highway diesel side, engine manufactures intend to deal with the pollution problems by catalytic converter technology. New converter technology for diesel engines is effectively reducing the primary pollutants, particulate matter (soot) and ground level ozone precursors, (oxides of nitrogen, or $\mathrm{NO}_{\mathrm{X}}$ ). However, to do so requires near-zero sulfur levels in the fuels since sulfur acts as a poison to the catalysts. A similar situation exists with gasoline-fueled engines.

Producers for their part will need to reduce sulfur content in most of their distillate products in order to support the engine-makers' technology. To do so demands additional treatment of fuel intermediates to remove the sulfur, and this is having a variety of effects on these blend stocks that are the same ones used to produce diesel, heating oil, jet fuel and kerosene. Constraints on transportation and storage of the fuels have created additional problems related to when and where to inject additives to finish the products.

Effects on burner fuels - For the oilheat industry, the changes under way on the diesel side of the fuel industry will likely have a number of effects on heating oil.

- Hydrotreating will become more prevalent with many streams in the refinery to attain the overall reduction in sulfur levels for a large portion of distillate fuels. This process reduces fuel sulfur and in doing so also reduces fuel nitrogen (which contributes fairly significantly to the $\mathrm{NO}_{\mathrm{X}}$ emissions of a low $\mathrm{NO}_{\mathrm{X}}$ burner). The lower sulfur / nitrogen blend stocks will likely find their way into heating oil and will help to dilute the sulfur in higher sulfur blend stocks to more desirable levels. Hydro-treating can also help to stabilize the blend stocks somewhat by tying up the reactive ends of molecules. The more severe hydrotreating required for the ultra low sulfur levels may also contribute to reducing viscosities somewhat.

- Simplifying the production process to help accommodate the new processes and requirements will likely reduce the number of product streams. As this occurs, stocks that can be blended into a larger number of fuels will be favored over those that are more restricted. In the case of high sulfur products, these will generally be diverted to residual products (including bunker fuels and asphalts) that are more tolerant of the higher sulfur levels rather than risk contaminating a more strictly regulated fuel. Having common specification limits among many fuels is a key advantage here for the producers.

- The use of the pipeline infrastructure can have some variable effects on heating oil, since the pipeline interfaces (the slug of mixed products that separates two products being transported sequentially) often are blended into heating oils. Because of the more divergent property restrictions between similar products (sulfur is a good example here) the interfaces are expected to increase to avoid contamination of the more restrictive fuel with the less restrictive fuel. The sheer volume of the interfaces will tend to accumulate, especially near the ends of a pipeline, so this effect will tend to have more of a local impact. The effects will depend on the products in the interface mixture. 
Since the processes for producing, treating, shipping and blending are not yet firm (the first regulations do not take effect until 2006) there are many unknowns. However, given the level of planning and investment going into preparing for the new fuel regulations, the general feeling among the product and process experts is that the overall quality of the national fuel supply will improve (at least from a sulfur level perspective).

\section{Model}

To evaluate the potential of a change in viscosity, a model was created based on classical fluid mechanics and thermodynamics. Flow can be predicted knowing the starting flow rate and the base and hypothesized viscosities. These flow rates are directly proportional to heat input rates using the higher heating value for grade 2 fuel. Flow rates also determine the air-fuel ratio based on specific gravity and using a constant combustion air flow rate which is fixed at set-up. Combustion effects then can be predicted knowing air-fuel ratios.

Flow through a simplex nozzle has been observed to vary as a function of the ratio of viscosities ${ }^{(2)}$ :

$$
\mathrm{F}_{2}=\mathrm{F}_{1} \cdot\left(\mathrm{v}_{2} / \mathrm{v}_{1}\right)^{0.15}
$$

where $F_{1}$ and $F_{2}$ are flows at viscosities $v_{1}$ and $v_{2}$, respectively. As viscosity increases, flow increases. Although this may seem counter-intuitive, the flow stream through the final orifice is an annulus, and the thickness of the annular wall increases as viscosity increases. ${ }^{(3)}$ This can be seen graphically in Figure 1. Flow conditions were calculated based on this relationship.

Combustion effects were defined as $\% \mathrm{CO}_{2}$ in the flue gas, and were calculated using a second order regression equation that gives $\% \mathrm{CO}_{2}$ as a function of air-fuel (A-F) ratio. ${ }^{(4)}$ The assumptions for the calculations were $14.36 \mathrm{lbm}$ of air per 1.00 $\mathrm{lbm}$ fuel oil yielding a stoichiometric blend at $15.3 \% \mathrm{CO}_{2}$. This relationship is shown graphically in Figure 2 (Appendix).

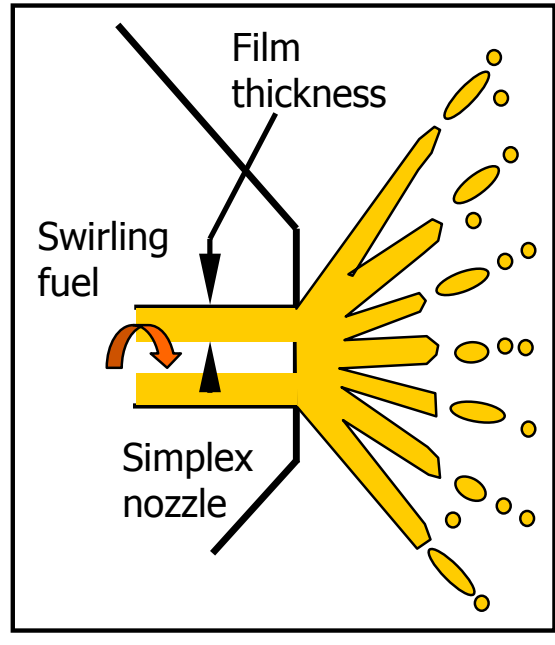

Figure 1 - Simplex nozzle operation.

\section{Data and assumptions}

The fuel data underlying the model and analysis is a composite of the data reported by NIPER and its successor organizations, TRW and Northrop-Grumman, from their 1995 through 2003 Heating Oil and Diesel Fuel analyses (less the 1998 data which was not available). ${ }^{(5)-(10)}$ The data included (205) heating oil samples and (460) diesel fuel samples and the distributions are shown in Table 1 and graphically in Figures 3 and 4 (Appendix). The data represented all market regions of the United States reporting fuel properties to NIPER. Three assignable cause outliers were removed from the heating oil data (out-of-specification viscosities marketed into the Southern U.S. region). The data in both the heating oil and diesel fuel samples were essentially normally distributed, and calculations were based on the properties of a normal distribution. The annual data sets appeared to be normal and in control when evaluated over time. 
Table 1 - Heating oil and Diesel fuel viscosity data summary.

\begin{tabular}{|l|c|c|c|c|c|}
\hline & $\mathrm{N}$ & $\begin{array}{c}\text { Mean } \\
\text { vis @ }\end{array}$ & $\begin{array}{c}\text { Std } \\
\text { Dev. }\end{array}$ & $\begin{array}{c}\text { Min. Vis } \\
\text { (95 Percnt'I) }\end{array}$ & $\begin{array}{c}\text { Max. Vis } \\
\text { (95 Percnt'I) }\end{array}$ \\
\hline Heat Oil & 205 & 2.496 & 0.3800 & 1.75 & 3.24 \\
\hline All Diesel & 460 & 2.668 & 0.3895 & 1.90 & 3.43 \\
\hline Highway Diesel & 371 & 2.659 & 0.3763 & 1.92 & 3.40 \\
\hline O-H'way Diesel & 89 & 2.703 & 0.4217 & 1.88 & 3.53 \\
\hline
\end{tabular}

The differences in viscosity ranges are statistically significant, with the mean viscosity of the diesel fuel pool higher than the heating oil pool by $0.17 \mathrm{cSt}$. The ranges of the two distributions are similar based on essentially similar standard deviations of the two pools $(0.38$ versus $0.39 \mathrm{cSt})$. Although this difference in viscosity is statistically significant, the practical effects on performance is the deciding factor in judging the difference as truly significant.

The hypotheses of the model were based on the likelihood of an extreme fuel viscosity change between appliance set-up (where normal variation is compensated by good practice) and a subsequent delivery. Industry standard set-up conditions consistent with good practice and manufacturers' typical recommendations were used to establish performance baselines.

The extreme changes were hypothesized based on $0.1 \%, 5 \%$ and $10 \%$ probabilities of an occurrence. In these scenarios, the worst-case was the $0.1 \%$ probability, the possible-case was the $5 \%$ probability and the common-case was the $10 \%$ probability. To determine these cases, the viscosities representing the probability of a minimum viscosity fuel and the probability of a maximum viscosity fuel being delivered were calculated from the distributions.

Heat input effects - Variation was predicted by comparing maximum viscosity flow rates with nominal viscosity flow rates, since the heat input of appliances is rated based on the nominal fuel flow associated with a specific nozzle and fuel pressure condition. (Calculations were made for a 1.00 gph nozzle at pressures ranging from 100-200 psig.) Minimum viscosity flow rates merely reduce the heat input rate without affecting appliance rating and minimally affecting performance.

Combustion effects - It was hypothesized that the appliance was set up using either one of two common set-up combustion conditions $\left(11.0\right.$ or $\left.11.5 \% \mathrm{CO}_{2}\right)$ at either mean or minimum viscosity, and that a subsequent delivery (before the set-up changed) was at maximum viscosity. Dilution of the delivery by fuel already in the tank was ignored to maximize the effect, although this would be a mitigating circumstance. Combustion effects variation was predicted based on the comparing maximum viscosity air-fuel ratio $\% \mathrm{CO}_{2}$ 's, and calculations were independent of fuel flow rate (i.e., flow rates were held constant).

\section{Analysis of the model}

For the purpose of evaluating the different viscosity range scenarios, current conditions were based on the heating oil data, and future state conditions were based on the combined diesel fuel data. The combined diesel fuel data includes both the $500 \mathrm{ppm}$ sulfur highway fuels and the $5000 \mathrm{ppm}$ sulfur off-highway fuels, and would arguably represent a combined heating oil / diesel fuel mix. Detailed analysis of highway and off-highway diesel data showed similar results to the combined 
diesel fuel results.

Heat Input - Considering the elevation in heat input rates over appliance rating with the maximum viscosity fuels, the flow rates are on the same order for both heating oil and the diesel fuel. Heat input rate has a potential to thermally overload the appliance, and must be evaluated on this basis, considering margins and safety factors. Although individual appliance would need to be evaluated by the manufacturer, a typically $1 \%$ increase in heat input (comparing maximum viscosity heating oil flow rates with maximum viscosity diesel fuel flow rates) is not likely significant. Calculated flow rates based on the various expected viscosities at varying fuel pressures are shown in Table 2. As expected, the worst-case (as defined above) scenario shows the greatest effect with increases between nominal and high viscosity heat inputs of 3.8\% and $4.7 \%$ for heating oil and diesel, respectively. This represents just under a $1 \%$ increase in heat input increase for the diesel fuels. Other scenarios (Tables 3 and 4 ) project minimal impact.

Table 2 - Worst case scenario heat input shift.

\begin{tabular}{|c|c|c|c|c|c|c|c|}
\hline \multicolumn{8}{|c|}{ Viscosity shift risk $\leq 0.1 \%(99.9 \%$ cases better $):$} \\
\hline \multirow{2}{*}{ Vis (cSt) } & Low & Mean & High & Low & & & High \\
\hline & 1.786 & 2.496 & 3.206 & 1.944 & & & 3.392 \\
\hline Pressure (psi) & \multicolumn{7}{|c|}{ Flow rate (gph) } \\
\hline 100 & 0.95 & 1.00 & 1.04 & 0.96 & & & 1.05 \\
\hline 120 & 1.04 & 1.10 & 1.14 & 1.05 & & & 1.15 \\
\hline 140 & 1.13 & 1.18 & 1.23 & 1.14 & & & 1.24 \\
\hline 160 & 1.20 & 1.26 & 1.31 & 1.22 & & & 1.32 \\
\hline 180 & 1.28 & 1.34 & 1.39 & 1.29 & & & 1.40 \\
\hline \multirow[t]{5}{*}{200} & 1.34 & 1.41 & 1.47 & 1.36 & & & 1.48 \\
\hline & \multicolumn{7}{|c|}{ Increase in heat input: } \\
\hline & \multirow{2}{*}{\multicolumn{3}{|c|}{$\begin{array}{l}\text { Heating oil } \\
\text { Nom to } \mathrm{Hi}\end{array}$}} & \multicolumn{4}{|c|}{ Diesel (all) } \\
\hline & \multirow{2}{*}{\multicolumn{3}{|c|}{$\begin{array}{c}\text { Nom to } \mathrm{Hi} \\
3.8 \%\end{array}$}} & \multicolumn{2}{|c|}{ Nom to $\mathrm{Hi}$} & \multicolumn{2}{|c|}{ Hi HO to Hi DF } \\
\hline & & & & \multicolumn{2}{|c|}{$4.7 \%$} & \multicolumn{2}{|c|}{$0.9 \%$} \\
\hline
\end{tabular}

Table 3 - Possible case scenario heat input shift.

\begin{tabular}{|c|c|c|c|c|c|c|}
\hline Viscosity shift risk $\leq \mathbf{5 \%}$ (95\% cases better): \\
\hline \multirow{2}{*}{ Vis (cSt) } & Low & Mean & High & Low & Mean & High \\
\cline { 2 - 7 } & $\mathbf{2 . 2 0 6}$ & $\mathbf{2 . 4 9 6}$ & $\mathbf{2 . 7 8 6}$ & $\mathbf{2 . 3 7 2}$ & $\mathbf{2 . 6 6 8}$ & $\mathbf{2 . 9 6 4}$ \\
\hline Pressure (psi) & \multicolumn{7}{|c|}{ Flow rate (gph) } \\
\hline $\mathbf{1 0 0}$ & 0.98 & 1.00 & 1.02 & 0.99 & 1.01 & 1.03 \\
\hline $\mathbf{1 2 0}$ & 1.08 & 1.10 & 1.11 & 1.09 & 1.11 & 1.12 \\
\hline $\mathbf{1 4 0}$ & 1.16 & 1.18 & 1.20 & 1.17 & 1.19 & 1.21 \\
\hline $\mathbf{1 6 0}$ & 1.24 & 1.26 & 1.29 & 1.25 & 1.28 & 1.30 \\
\hline $\mathbf{1 8 0}$ & 1.32 & 1.34 & 1.36 & 1.33 & 1.35 & 1.38 \\
\hline $\mathbf{2 0 0}$ & 1.39 & 1.41 & 1.44 & 1.40 & 1.43 & 1.45 \\
\hline & \multicolumn{7}{|c|}{ Increase in heat input: } \\
\cline { 2 - 7 } & \multicolumn{7}{|c|}{ Nom to Hiesel (all) } \\
\cline { 2 - 7 } & \multicolumn{7}{|c|}{ 1.7\% } & \multicolumn{7}{|c|}{ Nom to Hi } & Hi HO to Hi DF \\
\cline { 2 - 7 } & \multicolumn{7}{|c|}{$0.9 \%$} \\
\hline
\end{tabular}


Table 4 - Common case scenario heat input shift.

\begin{tabular}{|c|c|c|c|c|c|c|c|}
\hline \multicolumn{8}{|c|}{ Viscosity shift risk $\leq 10 \%(90 \%$ cases better $):$} \\
\hline \multirow{2}{*}{ Vis (cSt) } & Low & Mean & High & Low & & & High \\
\hline & 2.313 & 2.496 & 2.679 & 2.481 & & & 2.855 \\
\hline Pressure (psi) & \multicolumn{7}{|c|}{ Flow rate (gph) } \\
\hline 100 & 0.99 & 1.00 & 1.01 & 1.00 & & & 1.02 \\
\hline 120 & 1.08 & 1.10 & 1.11 & 1.09 & & & 1.12 \\
\hline 140 & 1.17 & 1.18 & 1.20 & 1.18 & & & 1.21 \\
\hline 160 & 1.25 & 1.26 & 1.28 & 1.26 & & & 1.29 \\
\hline 180 & 1.33 & 1.34 & 1.36 & 1.34 & & & 1.37 \\
\hline \multirow[t]{5}{*}{200} & 1.40 & 1.41 & 1.43 & 1.41 & & 43 & 1.44 \\
\hline & \multicolumn{7}{|c|}{ Increase in heat input: } \\
\hline & \multicolumn{3}{|c|}{ Heating oil } & \multicolumn{4}{|c|}{ Diesel (all) } \\
\hline & \multicolumn{3}{|c|}{ Nom to $\mathrm{Hi}$} & \multicolumn{2}{|c|}{ Nom to $\mathrm{Hi}$} & \multicolumn{2}{|c|}{$\mathrm{Hi} \mathrm{HO}$ to Hi DF } \\
\hline & \multicolumn{3}{|c|}{$1.1 \%$} & \multicolumn{2}{|c|}{$2.0 \%$} & \multicolumn{2}{|c|}{$1.0 \%$} \\
\hline
\end{tabular}

Combustion Effects - Higher viscosity fuel flow rates with a constant air flow decreases the A-F ratio, raising $\% \mathrm{CO}_{2}$, and potentially generating smoke depending on the burner and appliance. Considerations here include:

- $\quad \% \mathrm{CO}_{2}$ 's $>12.0 \%$ are considered potential smoke problems (application / installation specific).

- Differentials in $\% \mathrm{CO}_{2}$ from set-up to subsequent operation $>1.0 \%$ can create potential smoke problems (application / installation specific).

- Margin between set-up $\% \mathrm{CO}_{2}$ and smoke point $\% \mathrm{CO}_{2}$ is needed to counter potential air restriction (from lint, dust, hair, etc.).

Using these considerations in the evaluation, Table 5 shows that the worst-case scenario predicts relatively high $\% \mathrm{CO} 2$ and potential to generate smoke with either the heating oil or diesel fuel extremes. The shaded areas in the tables indicate $\mathrm{CO}_{2}$ levels for situations where these conditions could exist. Setting up the burner at a higher \%CO2 exacerbates the situation. The possible-case scenario (Table 6) predicts only a slight increase in $\% \mathrm{CO} 2 /$ smoke potential, and the common-case scenario (Table 7 ) predicts a minimal and probably unnoticeable change in $\% \mathrm{CO} 2$.

Table 5 - Worst-case scenario - combustion shift.

\begin{tabular}{|c|cccc|c|c|c|}
\hline Viscosity shift risk $\leq \mathbf{0 . 1 \%}$ (99.9\% cases better): \\
\hline$(Z=1.86)$ & Viscosity & High & Setup CO2 & $\begin{array}{c}\text { S/U @ Mean Vis, } \\
\text { \% CO2 @ High }\end{array}$ & $\begin{array}{c}\text { S/U @ Low Vis, } \\
\text { \% CO2 @ High }\end{array}$ \\
\hline Heating Oil & 2.496 & 0.3816 & 1.786 & 3.206 & $11.0 \%$ & $11.4 \%$ & $12.1 \%$ \\
Diesel (all) & 2.668 & 0.3895 & 1.944 & 3.392 & $11.0 \%$ & $11.4 \%$ & $12.0 \%$ \\
\hline Heating Oil & 2.496 & 0.3816 & 1.786 & 3.206 & $11.5 \%$ & $12.0 \%$ & $12.7 \%$ \\
Diesel (all) & 2.668 & 0.3895 & 1.944 & 3.392 & $11.5 \%$ & $12.0 \%$ & $12.6 \%$ \\
\hline
\end{tabular}


Table 6 - Possible-case scenario - combustion shift.

\begin{tabular}{|c|c|c|c|c|c|c|c|}
\hline \multicolumn{8}{|c|}{ Viscosity shift risk $\leq 5 \%(95 \%$ cases better $):$} \\
\hline \multirow[t]{2}{*}{$(Z=0.76)$} & \multicolumn{4}{|c|}{ Viscosity } & \multirow[b]{2}{*}{ Setup $\mathrm{CO}_{2}$} & \multirow{2}{*}{$\begin{array}{c}\text { S/U @ Mean Vis, } \\
\% \text { CO2 @ High }\end{array}$} & \multirow{2}{*}{$\begin{array}{l}\text { S/U @ Low Vis, } \\
\% \text { CO2 @ High }\end{array}$} \\
\hline & Mean & Stdev & Low & High & & & \\
\hline \begin{tabular}{|l|} 
Heating Oil \\
\end{tabular} & 2.496 & 0.3816 & 2.206 & 2.786 & $11.0 \%$ & $11.2 \%$ & $11.4 \%$ \\
\hline Diesel (all) & 2.668 & 0.3895 & 2.372 & 2.964 & $11.0 \%$ & $11.1 \%$ & $11.4 \%$ \\
\hline \begin{tabular}{|l|} 
Heating Oil \\
\end{tabular} & 2.496 & 0.3816 & 2.206 & 2.786 & $11.5 \%$ & $11.7 \%$ & $11.9 \%$ \\
\hline Diesel (all) & 2.668 & 0.3895 & 2.372 & 2.964 & $11.5 \%$ & $11.7 \%$ & $11.9 \%$ \\
\hline
\end{tabular}

Table 7 - Common-case scenario - combustion shift.

\begin{tabular}{|c|cccc|c|c|c|}
\hline \multicolumn{7}{|c|}{ Viscosity shift risk $\leq \mathbf{1 0} \% \mathbf{( 9 0 \%}$ cases better): } \\
\hline (Z= 0.48) & Mean & Stdev & Low & High & Setup CO2 & $\begin{array}{c}\text { S/U @ Mean Vis, } \\
\text { \% CO2 @ High }\end{array}$ & $\begin{array}{c}\text { S/U @ Low Vis, } \\
\text { \% CO2 @ High }\end{array}$ \\
\hline Heating Oil & 2.496 & 0.3816 & 2.313 & 2.679 & $11.0 \%$ & $11.1 \%$ & $11.2 \%$ \\
Diesel (all) & 2.668 & 0.3895 & 2.481 & 2.855 & $11.0 \%$ & $11.1 \%$ & $11.2 \%$ \\
\hline Heating Oil & 2.496 & 0.3816 & 2.313 & 2.679 & $11.5 \%$ & $11.6 \%$ & $11.8 \%$ \\
Diesel (all) & 2.668 & 0.3895 & 2.481 & 2.855 & $11.5 \%$ & $11.6 \%$ & $11.8 \%$ \\
\hline
\end{tabular}

Even when two faults are combined (i.e., the common case viscosity change and a change from nominal to high flow nozzle without re-setting the burner as shown in Table 8) the predicted effects are less potentially serious than the worst-case scenario.

Table 8 - Common-case with high flow nozzle scenario - combustion shift.

\begin{tabular}{|c|c|c|c|c|c|c|c|}
\hline \multicolumn{8}{|c|}{ Viscosity shift risk $\leq 10 \%(90 \%$ cases better $)+$ High tolerance Nozzle (double fault): } \\
\hline \multirow[t]{2}{*}{$(Z=0.48)$} & \multicolumn{4}{|c|}{ Viscosity } & \multirow[b]{2}{*}{ Setup $\mathrm{CO}_{2}$} & \multirow{2}{*}{$\begin{array}{c}\text { S/U @ Mean Vis, } \\
\% \text { CO2 @ High }\end{array}$} & \multirow{2}{*}{$\begin{array}{l}\text { S/U @ Low Vis, } \\
\% \text { CO2 @ High }\end{array}$} \\
\hline & Mean & Stdev & Low & High & & & \\
\hline Heating Oil & 2.496 & 0.3816 & 2.313 & 2.679 & $11.0 \%$ & $11.7 \%$ & $11.9 \%$ \\
\hline Diesel (all) & 2.668 & 0.3895 & 2.481 & 2.855 & $11.0 \%$ & $11.7 \%$ & $11.8 \%$ \\
\hline Heating Oil & 2.496 & 0.3816 & 2.313 & 2.679 & $11.5 \%$ & $12.3 \%$ & $12.4 \%$ \\
\hline Diesel (all) & 2.668 & 0.3895 & 2.481 & 2.855 & $11.5 \%$ & $12.3 \%$ & $12.4 \%$ \\
\hline
\end{tabular}

\section{Conclusions and Recommendations}

Changing the viscosity of the fuel oil standard is not likely to have a significant effect on burner performance in an appliance based on changes in heat input and combustion.

- Heat input with a future state fuel similar to today's diesel fuel could increase by about $1 \%$ when compared to the current state fuel under worst-case conditions.

- Combustion with a future state fuel similar to today's diesel fuel could perform essentially the same when compared to the current state fuel under worst-case conditions. $\% \mathrm{CO}_{2}$ would increase approximately $1 \%$ from the set-up point.

The advantages to the oilheat industry of greater commonality of heating oil with the higher volume and more strictly regulated diesel fuel suggest that a change in viscosity range is in order. Performance is not significantly compromised, and there is reasonable potential to see improved properties with a future state fuel aligned with diesel fuel. Continued monitoring by the oilheat industry is warranted, especially during the transition period. 


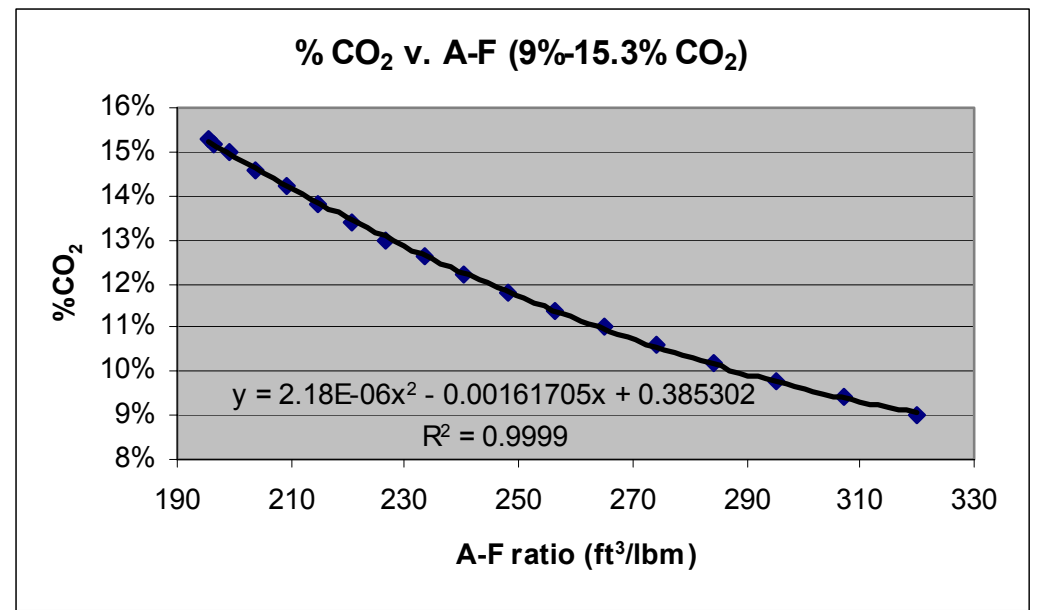

Figure 2 - $\mathrm{CO}_{2}$ as function of A-F ratio.

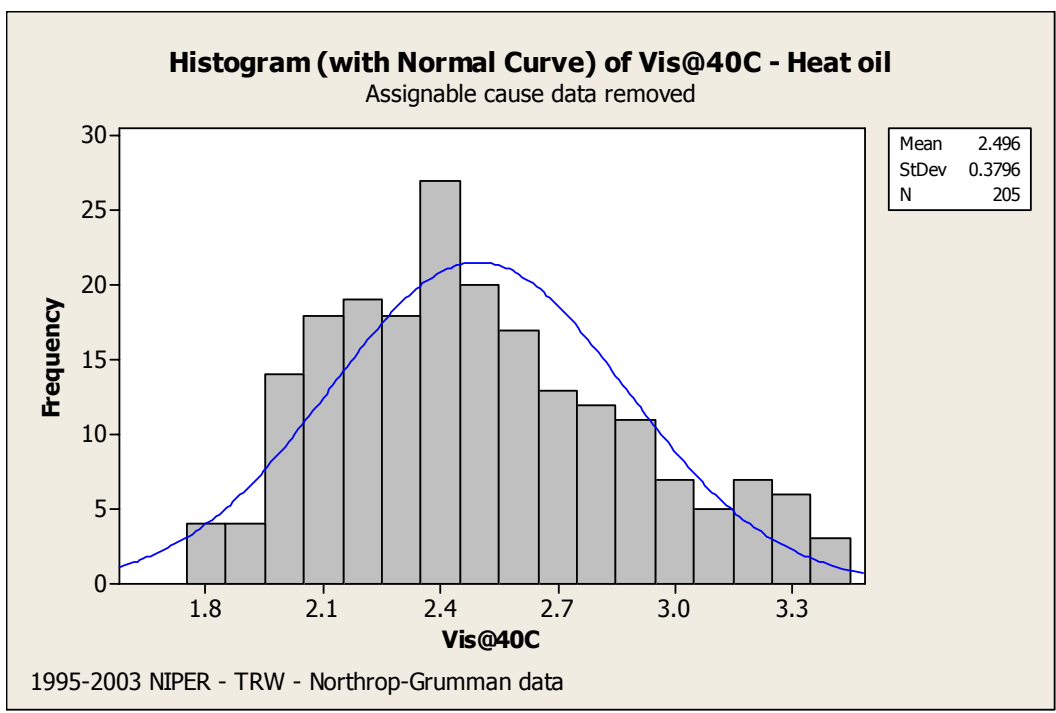

Figure 3 - Heating oil viscosity distribution.

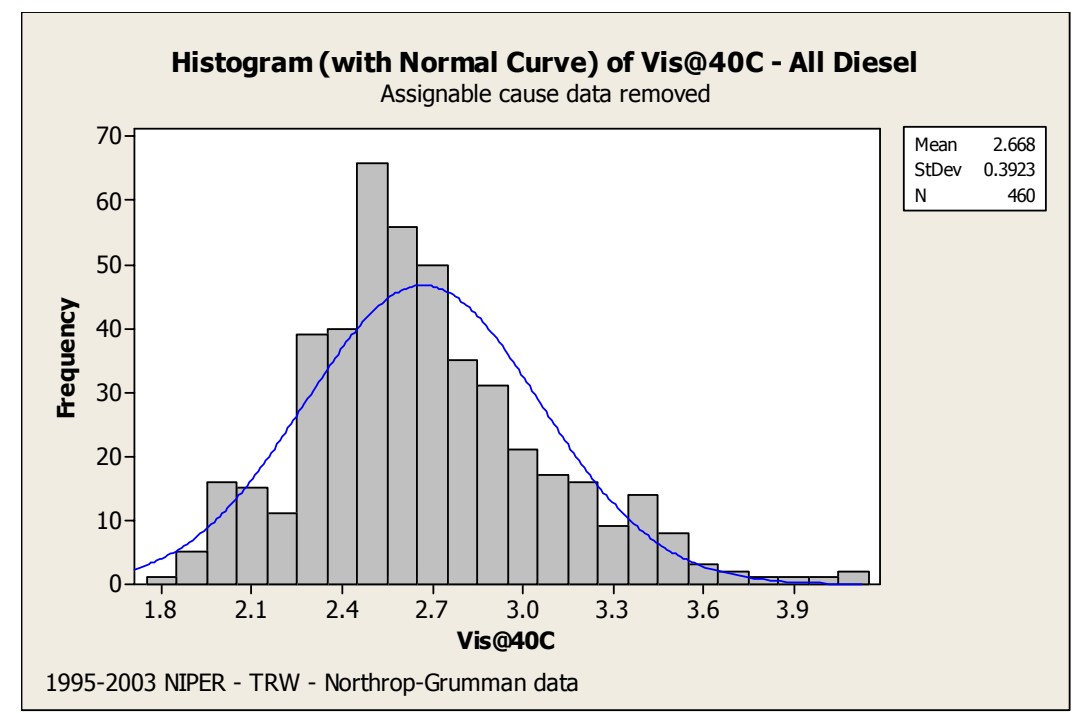




\section{Figure 4 - Diesel fuel viscosity distribution.}

\section{REFERENCES:}

1. The Dieselization of America, Cameron, C., World Diesel 2003. Hart Energy Publications, 2003.

2. Empirical flow rate results from different viscosity fuels in simplex nozzles (unpublished data), Panchagnula, M., Delavan Inc., a division of BF Goodrich Co., 2000.

3. Peep into the Nozzle Using Computational Fluid Dynamics!, Panchagnula, M., Proceedings of the 2001 National Oilheat Research Alliance Technology Conference, 2001.

4. Marks' Standard Handbook for Mechanical Engineers, Avallone, E.A. \& Baumeister III, T., Ninth Ed., 1987.

5. Heating Oils, 1995, -96, -97, Dickson, C.L. \& Sturm, Jr., G.P., BDM Petroleum Technologies, 1995, 1996, 1997.

6. Heating Oils, 1999, 2000, -01, 02, Dickson, C.L., TRW Petroleum Technologies, 1999, 2000, 2001, 2002.

7. Heating Oils, 2003, Dickson, C.L., Northrop Grumman, 2003.

8. Diesel Fuel Oils, 1995, -96, -97, Dickson, C.L. \& Sturm, Jr., G.P., BDM Petroleum Technologies, 1995, 1996, 1997.

9. Diesel Fuel Oils, 1999, 2000, -01, 02, Dickson, C.L., TRW Petroleum Technologies, 1999, 2000, 2001, 2002.

10. Diesel Fuel Oils, 2003, Dickson, C.L., Northrop Grumman, 2003. 
Paper No. 03-04

New York State market demonstration of low sulfur fuel oil

\author{
Roger J. McDonald \\ Brookhaven National Laboratory \\ Building 526 \\ 12 North Six Street \\ Upton, NY 11973 \\ Phone: 631-344-4197 \\ Fax: 631-344-2359 \\ E-mail: mcdonald@bnl.gov \\ Internet: www.bnl.gov \\ and \\ John Batey, PE \\ Energy Research Center, Inc. \\ 35 Fawn Rd. \\ Easton, CT 06612 \\ (203) 459-0353 \\ E-mail: erc@optonline.net
}




\title{
New York State Market Demonstration of Low Sulfur Fuel Oil
}

\author{
John E. Batey, Energy Research Center Inc. \\ Roger J. McDonald, Brookhaven National Laboratory
}

The New York State Energy Research and Development Authority recently completed a three-year project that has clearly demonstrated the important marketing and environmental advantages associated with the distribution of low sulfur heating oil. The study included over 1,000 homes in upstate New York. The project was made possible by the cooperation of the Buhrmaster Energy Group located in Scotia, New York including the crucial in-field assistance received from the company's staff under the direction of James and Kenneth Buhrmaster. Energy Research Center Inc. conducted the study with support from Brookhaven National Laboratory.

\section{Background Laboratory Investigation}

Brookhaven National Laboratory has documented the advantages of using low sulfur fuel oil as heating oil in several technical reports and papers starting around 1990. These include reduced combustion related emissions, mainly sulfur dioxide but also other forms of sulfur oxides including sulfites and sulfates in much smaller percentages (for more detail see box). The sulfur in No. 2 heating fuel is generally not a good thing at the current levels of 0.20 to 0.25 percent by weight. A very tiny amount of sulfur content is good for lubrication properties but even this tiny level is much lower and well within the 0.05 percent level (500 parts per million) which defines low sulfur heating oil. Sulfur contributes significantly to heat exchanger fouling and requires periodic cleanings by a service technician. The "soot" that is cleaned from heat exchangers is actually a combination of things; about fifty to sixty percent by weight is iron sulfate or scale. The other major constituent is carbon related material resulting form the very tiny amount of fuel that is not burned completely. The hardest part to clean is the scale, which can be solidly encrusted on the metal surfaces requiring significant effort to remove. The fouling that builds up on a boiler restricts the heat transfer process and slowly degrades the performance of the heating appliance. The other sulfur related compounds contribute to air quality issues. This is a major issue that the oil heat industry is currently dealing with and one of the reasons that the National Oilheat Research Alliance adopted a resolution to promote the use of low sulfur heating fuel by its membership in April 2003. The issue of concern is fine particulates, those generated at the sources called "primary" and also those formed by the chemistry that occurs in the atmosphere or "secondary". The emission of sulfur dioxide and nitrogen oxides can eventually contribute to secondary particulates that are formed in the upper atmosphere and eventually fall back down to add to the ambient air quality that we breath.

Donald Allen, president of E.T. Lawson in Virginia and current chairman of NORA was the first oilheat marketer to pioneer the use of low sulfur fuel oil as a premium fuel on a wide scale. He based his marketing plan on the scientific results obtained from Brookhaven National Laboratory studies that indicated the many positive advantages of marketing low sulfur content fuel. Mr. Allen has provided this product to his customers 
for over ten years and reports significant benefits associated with its use in terms of reduced maintenance and better combustion. E.T. Lawson proved that low sulfur oil had an important role to play in the oilheat market. The next effort was to provide the industry with a well documented comparative market study that could clearly measure the metrics associated with the many benefits and any associated costs.

\section{The Chemistry of Sulfur and Fuel Oil Combustion}

The fuel bound sulfur in heating oil is released during the combustion process and forms several different types of sulfur oxides including sulfur dioxide, sulfites and sulfates. The majority of the sulfur forms sulfur dioxide, which is a gas and most of it vents out the chimney. The sulfur dioxide emitted into the atmosphere can eventually contribute to air quality issues associated with smog, acid rain and secondary fine particulates all generated by chemical reactions that occur with other air emissions and sunlight in the upper atmosphere. The sulfites can react with water vapor (steam that is also a product of the combustion process) and forms sulfuric acid that can condense on the heat exchanger surfaces resulting in corrosion and scale formation (iron sulfates). The sulfates generated by the combustion process are emitted to the atmosphere as fine particulates. These are small diameter or fine particulate mater (PM 2.5) less than 2.5 microns in size. The levels of PM2.5 from all sources are currently an issue of concern to the United States Environmental Protection Agency, which has designated several metropolitan areas as being out of compliance with air quality standards. It will be up to the states to form State Implementation Plans (SIP) to bring these areas into compliance in the next several years.

\section{NYSERDA Low Sulfur Market Demonstration}

The NYSERDA study was a blind study to evaluate the effects of marketing low sulfur heating fuel to average customers in over a thousand hones. The properties of the two fuels were basically identical except for the sulfur content. The average sulfur content of the baseline fuel was 0.145 percent sulfur (considerably lower than the national average of 0.22 percent) and the average sulfur content of the low sulfur product was about 0.045 percent. During the project, low sulfur fuel was delivered to an entire division of about 1,000 plus homes and a similar sized division using normal sulfur level fuel oil was also tracked as a baseline for comparison.

\section{Advantages}

The results can be can be categorized in to two types, economic advantages and environmental advantages.

\section{Economic Benefits}

The most significant result was that the number of service technicians was reduced by about 50 percent for the division that received low sulfur fuel in comparison to the baseline division. The effort to clean and maintain the heating equipment was 
significantly reduced. Prior to starting the low sulfur trial this division required an average of three service technicians. The effort required by the second and third years of the study was on average that of about one and a half full time equivalent service technicians. This resulted from the cleaner operation of the equipment resulting in reduced scale and corrosion on the fireside surfaces of the heat exchangers. The result of a separate project related to improving fuel performance conducted by BNL for NORA also suggests that low sulfur fuel may tend to be more stable than normal fuel. The data is limited and by no means exhaustive but indications from fuel stability tests are in the positive direction. The result of cleaner combustion, cleaner heat exchangers and possibly more stable fuel quality all contributed to a major reduction in the need for servicing the equipment and resulted in a reduction in the number of technicians assigned to the delivery division that received the low sulfur fuel.

In carefully controlled laboratory studies there was also a slight positive shift in efficiency over time. The rate at which system efficiency degrades is on the order of one to two percent per year using normal fuel. The reduction in scale and corrosion buildup from burning low sulfur content fuel slows the degradation process resulting in maintaining higher efficiency. In the field study, the analysis of the fuel delivery data and a K-factor analysis did not indicate any detectable differences between the low sulfur delivery division and the normal sulfur delivery division. The low precision of the Kfactor technique was apparently too large to detect such a small variation even when applied to a large sample of homes. Variables encountered in the field study that contributed to this included customers who were added or deleted, customers who may have had fuel deliveries from other sources, and weather variables not taken in to account with the $\mathrm{K}$-factor degree day system.

What was detected was a clear indication that the heating systems had cleaner heat exchangers when low sulfur fuel was marketed in place of normal sulfur content ASTM No. 2 heating oil. This was true both in the broad based sense using a new figure of merit, the fouling scale, which was used to document over a hundred homes including a smaller sample of homes where the heating systems were disassembled and cleaned thoroughly collecting the debris that was recovered for later analysis in the laboratory. The fouling scale used was developed by BNL and is a visual technique to determine the degree of fouling on a scale of one to five. This was accomplished by the service technicians who upon opening the unit prior to cleaning were asked to compare what they saw to a series of pictures on a numbered chart to determine how clean or dirty the heat exchanger appeared and mark down the value on the one to five scale. The pictures on the scale were actually obtained from similar heat exchangers that had been exposed to fuels with a range of sulfur contents simulating a full year of operation in a prior laboratory study. In the group of homes where, both the fouling scale and manual collection techniques were used, the average ratio of the fouling scale numbers was 1.8 (normal sulfur to low sulfur) and the ratio of the actual mass collected was 2.0 ( 0.28 pounds with normal sulfur to 0.14 pounds with low sulfur fuel). This provides a clear indication that cleaner operation was obtained with the use of low sulfur fuel heating oil. The fouling scale is not an absolute quantitative measure, it is merely an indicator of the condition of the unit, how clean or dirty it is or more to the point how much effort it will be required to clean the heat 
exchanger. It does provide a quick method of documenting the benefit of cleaner operation resulting in cleaner heat exchangers when low sulfur content fuel is used.

Cleaner heat exchangers equate to lower annual service costs and reduced labor required to maintain the heating systems on an annual basis. The results of this study indicate that the time between cleanings could be doubled. In fact the result obtained by the Buhrmaster Energy Group indicates that the systems actually required significantly less maintenance in general and they were able to reduce the number of service technicians assigned to the delivery zone receiving the low sulfur product from three down to the equivalent of one and half full time technicians by the second and third years. The operational benefits when marketing low sulfur product are quite significant.

One additional benefit noted during the field study was that the service technicians voiced a preference for working in homes where low sulfur fuel was delivered. Apparently the reduced sulfur content resulted in a more neutral (or pleasing) odor and this was noticeable to the service technicians assigned to perform work in these homes. This was an unexpected but pleasant additional to the list of benefits associated with the low sulfur fuel. This may or may not be at a level where the homeowner can actually tell the difference but if so it is yet another positive benefit to be associated with this premium product.

\section{Environmental Benefits}

Concerns over environmental emissions continue to be front-page issues in the news headlines. Fuel oil marketers that choose to market a low sulfur content heating oil product can benefit greatly from the environmental advantages associated with its use. The vast majority of the sulfur content of fuel oil is converted to sulfur dioxide in the combustion process and by reducing the sulfur you reduce the emissions in similar percentages. If as in this study the initial sulfur level is 0.145 percent, which is actually quite low to begin with, and the low sulfur product averages 0.045 percent, the expected reduction in sulfur dioxide is approximately seventy percent. If the sulfur content of the normal fuel oil was determined to be closer to published national average of 0.20 to 0.25 percent sulfur, the reduction in sulfur dioxide would be closer to eighty percent. In either case this is a significant reduction that will benefit everyone with better air quality. A similar reduction can also be expected for the emission of that portion of the fine particulates (PM 2.5) in the form of sulfates and sulfites. Data obtained from the CANMET Energy Resources Center related to particulate measurements with fuels of various sulfur content clearly indicate that a major portion of the fine particulate emission (PM 2.5) is related to sulfur content in the fuel. Techniques used to remove sulfur in the refinery process also tend to reduce the nitrogen content of the fuels as well. This has a small benefit in that the portion of the fuel related nitrogen oxides (NOx) emission will also be reduced. The majority of the NOx emission is related to nitrogen that makes up about seventy percent of ambient air and therefore it is unavoidably in the combustion air used by the oil burners in the heating equipment resulting in large amounts of thermal NOx which is the main source of NOx in small residential oil burners. 


\section{Cost Factors}

There are numerous advantages and benefits that can be associated with the marketing of low sulfur content fuel. The one issue of concern is the additional cost associated with the fuel. To lock in the availability of the fuel for the purposes of this market study the fuel supply was contracted for in advance and the price was locked in during the summer period prior to the winter heating season, the cost differential being approximately four cents per gallon. We believe the cost factor for this study is unusually high and more a result of the fact that this fuel required special handling as low sulfur heating oil is not normally available at the Port of Albany on the Hudson river which was the source of the product at the wholesale level during this study. Recently the average New York Harbor Spot price of low sulfur diesel fuel compared to No. 2 heating oil was 1.6 cents per gallon during the period from January 2003 to March 2004 and this is more typical of the average wholesale price differential for the three years of the study. During brief periods of high market volatility this price differential may dramatically change as with any commodity that is traded on an exchange. The volatility in the differential cost has thus far been relatively small compared to the overall volatility of the price of light distillate fuel when supply is tight.

The NYSERDA report includes extensive detail on the cost benefits of marketing low sulfur fuel oil. The bottom line is that in general marketing low sulfur product is a winner in almost any market. If the cost of labor is extremely low it would require a more careful analysis but in almost all markets this isn't an issue. To gain the most out of marketing low sulfur fuel consider the option of extending the period between cleanings to two or more years depending on the early experience gained during initial marketing of this product. Energy Research Center has developed a service cost reduction program based on the results of the NYSERDA project.

\section{Summary}

In summary, low sulfur heating oil handles, stores and burns in the usual manner. The ASTM specification for low sulfur heating oil is exactly the same as for conventional heating oil with the lone exception of a requirement for a 0.05 percent by weight maximum for sulfur content. It is the same heating oil now delivered in every sense of the word, only better. 
Paper No. 04-04

\title{
Metal dusting in low- $\mathrm{NO}_{\mathrm{x}}$ recirculation burners for fuel oil
}

\author{
K. Lucka ${ }^{a}$, H. Ackermann ${ }^{a}$, H. Koehne ${ }^{a}$, L. Lucks ${ }^{b}$ \\ ${ }^{a}$ Oel-Wärme-Institut gGmbH, \\ Kaiserstr. 100, 52134 Herzogenrath (Germany) \\ ${ }^{\mathrm{b}}$ Institut für wirtschaftliche Oelheizung e.V., \\ Süderstr. 73a, 20097 Hamburg (Germany) \\ Phone: 02407-951816 \\ Fax: 02407-951818 \\ E-mail: K.Lucka@owi-aachen.de \\ Internet: www.OWI-Aachen.de
}




\title{
Metal dusting in low- $\mathrm{NO}_{\mathrm{x}}$ recirculation burners for fuel oil
}

\author{
K. Lucka ${ }^{a}$, H. Ackermann ${ }^{a}$, H. Koehne ${ }^{a}$, L. Lucks ${ }^{\text {b }}$ \\ ${ }^{a}$ Oel-Wärme-Institut gGmbH, Kaiserstr. 100, 52134 Herzogenrath (Germany) \\ ${ }^{\mathrm{b}}$ Institut für wirtschaftliche Oelheizung e.V., Süderstr. 73a, 20097 Hamburg
}

In future low sulfur fuel oil (LSFO) will be increasingly launched on the German market. LSFO is advantageous for low-temperature oil-fired boilers. Fouling and lowtemperature corrosion of the boiler are significantly reduced. Energy and costs are saved by its application in oil-fired condensing boilers. Here a neutralization of the condensate is no longer required. When burning low sulfur fuel oils in preliminary burner tests a tendency towards metal dusting of flame tubes and head-pieces of residential low- $\mathrm{NO}_{\mathrm{x}}$ burners has been observed. This paper resumes results of research into the effect on the corrosion of burner type, of parameters specific to the fuel, and of an additive. Evidence was found that the corrosion is enhanced by polycyclic aromatic hydrocarbons (PAH) and that the effect of the PAHs is inhibited by the additive 2-ethylhexylnitrat (2-EHN). By stepwise increasing the sulfur content of a low sulfur fuel oil via addition of benzothiophen it was found that the metal dusting tendency is first enhanced. But when the sulfur content exceeds a critical value the corrosion is inhibited. The effective amount of additive or sulfur depends on energy per unit area experienced by the flame tube.

\section{Introduction}

Since September 2003 the German standard DIN 51603 for liquid fuel specifies a low sulfur fuel oil. The sulfur content of this low sulfur fuel oil (LSFO) is limited to 50 $\mathrm{mg} / \mathrm{kg}$. Corrosion by metal dusting (MD) of flame tubes - made out of the Ni-Cr-based alloy Alloy 601 - was sporadically observed when burning LSFO in blue and yellow flame burners. A typical damage is shown in fig. 1. The corrosions attack appears as circular pits and holes. The $1 \mathrm{~mm}$ thick material is consumed within $300 \mathrm{~h}$ to $500 \mathrm{~h}$ burner running time.

In previous investigations the authors found that due to local fuel rich condition near the tube wall available oxygen is burned and hydrocarbon concentration is high there. In recirculation burners the MD mechanism involves the decomposition of these hydrocarbons whereas $\mathrm{CO}$ reduction or the Boudouard reaction are not relevant [1]. According to the present understanding of the MD mechanism for Ni-base alloys carbon atoms are adsorbed at catalytic active sites at the surface of the alloy. They migrate into the material. The concentration of carbon increases until the alloy is supersaturated with carbon. Then graphite is precipitated followed by the disintegration of the metallic matrix into small particles. These catalytically active particles amplify decomposition of hydrocarbons and formation of graphite. The graphite grows as whiskers and columns on the attacked surface region [2]. Cr-oxide formed on the $\mathrm{Ni}-\mathrm{Cr}$ alloys is not catalytically active. The corrosion attacks the high temperature alloy at defects in the oxide layer. Hence for these materials the typical forms of attack are pits and craters.

It is well known that MD is inhibited by even low concentrations of $\mathrm{H}_{2} \mathrm{~S}$ in the gas atmosphere [3; 4]. This effect is attributed to the deactivation of catalytically active surface sites by adsorbed sulfur atoms $[5 ; 6 ; 7]$. Hence it may be concluded that by the 


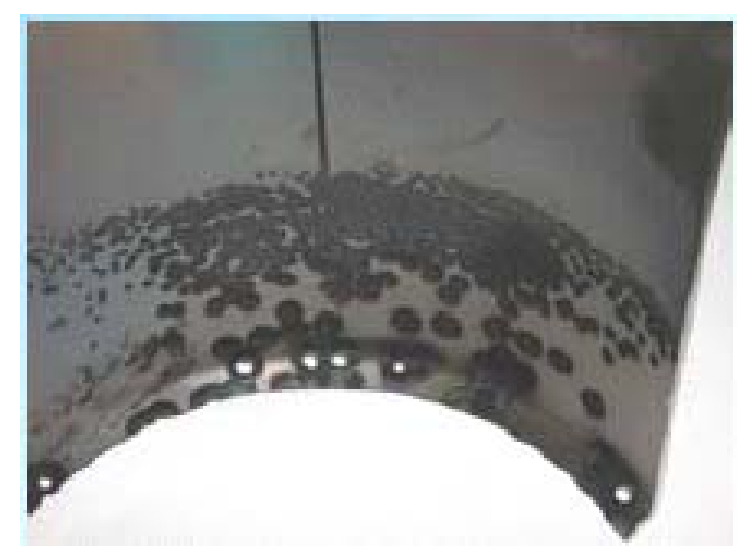

Figure 1.

Damage of a flame tube

burner operation time: $357 \mathrm{~h}$ same effect damage is prohibited when fuel oil with high sulfur content is burned and that for LSFO the effect fails because the concentration of sulfur is too low. Quantitative surface analysis gave evidence that the amount of sulfur chemisorbed on new flame tubes is sufficiently high for effective blockage of surface sites even for LSFOs [8].

This paper presents the results of a standardized burner test of a series of low sulfur fuel oils originating from different refineries [9]. A relationship between the corrosion and fuel composition was established.

Furthermore investigations of the effect of an additive and of sulfur content are reported.

\section{Experimental apparatus}

The experiments were performed with two different types of burner, a yellow flame burner and a blue flame burner. In the yellow flame burner flame stabilisation is achieved by a baffle. The burner is equipped with a flame tube - shown in figure $2-$ and operated in a commercial boiler. Exhaust gas is recirculated via a wide gap between air nozzle and flame tube. For the operation of the burner fuel and air supply were adjusted to a power of $27 \pm 0.3 \mathrm{~kW}$ and an air ratio of 1.15 . The burner was operated continuously. For every test a new flame tube was placed onto the burner. The tubes were manufactured from bright annealed $1 \mathrm{~mm}$ thick sheets of Alloy 601 (Ni-23Cr$14 \mathrm{Fe}-1.4 \mathrm{Al})$.

Under these conditions thirteen LSFOs from different refineries were burned in the yellow flame burner, see table 1. The burner tests were stopped after $65 \mathrm{~h}$ up to $75 \mathrm{~h}$ burner running time. For investigation of the effect of polycyclic aromatic hydrocarbons (PAH) and the additive 2-ethylhexylnitrat (2-EHN) a blend of the fuel oil T7 and a light cycle oil with high content of di- and tri-aromatics was used, see table 2.

The second test rig used was a modified blue flame burner operating in a standardized test boiler. The burner is equipped with a flame tube for flame-stabilization, see figure 3. The inner diameter of the flame tube is by a factor of 0.7 smaller than the tube diameter of the yellow flame burner. The tube - made of Alloy 601 - is the corrosion sample. The tests were performed at burner power $15 \mathrm{~kW}$. The concentration of oxygen in the exhaust gas was adjusted lambda of 1.15-\%. The burner was operating permanently from start to end of the test. Test time was $36 \mathrm{~min}$.

With the blue flame burner the LSOFs T5 and T7 were tested. Also the effect of sulfur was examined. A starting test with the LSFO T5 was performed. The sulfur content was varied by addition of benzothiophen $\mathrm{C}_{8} \mathrm{SH}_{6}$ to the fuel. For each mixture a test was performed with a new flame tube under same conditions as those of the starting test. The area of carbon deposition on the inner surface of each flame tube as seen by visual inspection was quantified. Additionally the tubes were optically investigated with a 
magnification factor of 80 . Thereby the type of the carbon deposition could be identified and a corrosion attack of the material could be detected.

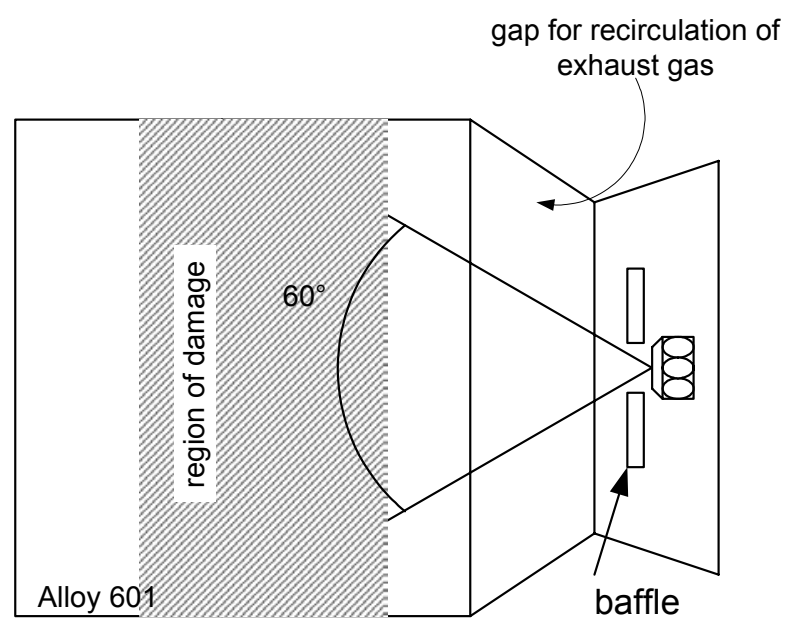

Figure 2.

Head piece of yellow flame burner

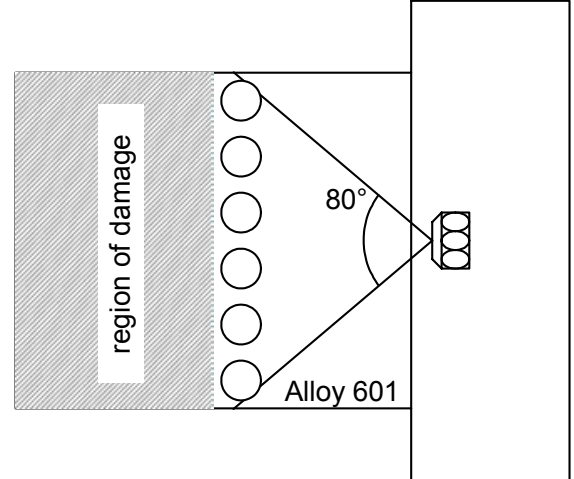

Figure 3.

Flame tube of blue flame burner

\section{Test results}

The composition and the results of the LSFOs are given in table 1. The fuels P13 to P5 are arranged in the table according to degree of corrosion in the yellow flame burner. It follows from the table, that MD correlates with sulfur content greater or equal $25 \mathrm{mg} / \mathrm{kg}$ and that the tendency towards MD increases with increasing content of di-aromatics. Exceptions of this rule are the fuels P13 with sulfur content of $7 \mathrm{mg} / \mathrm{kg}$ and P0 with 0.8 weight $\%$ di-aromatics. Corrosion attack on the inner surface of the tube of the blue flame burner was observed already after the short test times of 36 minutes for the fuel T5 and T7 which did not provoke any corrosion in the yellow flame burner.

The hypothesis that PAHs promote MD was checked by raise of the PAH content of fuel T7 to a value of 7 weight $\%$. The PAH-rich completely hydrogenated low cycle oil S1 was added, see table 2. Simultaneously the sulfur content was raised to $34 \mathrm{mg} / \mathrm{kg}$. In two independent tests MD pits were observed in the yellow flame burner already after 5 h. After adding the combustion improver 2-EHN to the fuel mixture $\mathrm{T} 7-30.8 \% \mathrm{~S} 1$ in proportion $1000 \mathrm{ppm}$ and $500 \mathrm{ppm}$ MD pits did not form within the same test time.

After test in the blue flame burner no difference of degree of corrosion between $\mathrm{T} 7$ and T7-30.8\% S1 existed. Also 2-EHN had no effect on the corrosion.

The most striking result of table 1 is that contrary to expectation no MD was observed for lowest sulfur contents. As in the above experiment along with PAH content the sulfur content was increased the PAH effect and a potential effect of sulfur are superposed. Hence an experiment was conducted where but the sulfur content was varied. By addition of benzothiophen $\mathrm{C}_{8} \mathrm{SH}_{6}$ to $\mathrm{T} 5$ fuels with sulfur contents of 67.5 $\mathrm{mg} / \mathrm{kg}, 125 \mathrm{mg} / \mathrm{kg}, 250 \mathrm{mg} / \mathrm{kg}$ and $500 \mathrm{mg} / \mathrm{kg}$ were realized and tested in the blue flame burner. 
Table 1 Composition of tested LSFO and test results

\begin{tabular}{|c|c|c|c|c|c|c|c|c|}
\hline fuel & additive & $\begin{array}{c}\text { sulfur } \\
\text { content }\end{array}$ & \multicolumn{4}{|c|}{ PAH in weight $\%$} & \multicolumn{2}{|c|}{ result of test } \\
\hline & & $\begin{array}{c}\text { in } \\
\mathrm{mg} / \mathrm{kg}\end{array}$ & $\begin{array}{c}\text { mono- } \\
\text { aromatics }\end{array}$ & $\begin{array}{c}\text { di- } \\
\text { aromatics }\end{array}$ & $\begin{array}{c}\text { tri- } \\
\text { aromatics }\end{array}$ & $\begin{array}{l}\text { total poly- } \\
\text { aromatics }\end{array}$ & $\begin{array}{c}\text { yellow } \\
\text { flame } \\
\text { burner }\end{array}$ & $\begin{array}{l}\text { blue } \\
\text { flame } \\
\text { buner }\end{array}$ \\
\hline T5 & none & 5 & 20,5 & 0,2 & 0,1 & 0,3 & \multirow{6}{*}{$\begin{array}{c}\text { no } \\
\text { MD }\end{array}$} & $\mathrm{MD}$ \\
\hline D3 & $\begin{array}{c}\mathrm{L}, \mathrm{FI}, \mathrm{A} \\
2-\mathrm{EHN}\end{array}$ & 5,3 & \multicolumn{4}{|c|}{ not known } & & \\
\hline $\mathrm{D} 2$ & L, FI, A & 9 & 18,6 & 0,5 & 0,2 & 0,7 & & not \\
\hline D4 & $\mathrm{FI}, \mathrm{A}$ & 9,6 & \multicolumn{4}{|c|}{ not known } & & \\
\hline D1 & FI, A & 10 & \multicolumn{4}{|c|}{ not known } & & \\
\hline $\mathrm{T} 7$ & $\mathrm{~L}, \mathrm{FI}, \mathrm{A}$ & 15 & 16 & 0,4 & 0,2 & 0,6 & & MD \\
\hline P13 & none & 7 & 22,8 & 0,8 & 1,1 & 1,9 & \multirow{7}{*}{ MD } & \multirow{7}{*}{$\begin{array}{c}\text { not } \\
\text { tested }\end{array}$} \\
\hline $\mathrm{P} 0$ & $\mathrm{~L}, \mathrm{FI}, \mathrm{A}$ & 72 & 28,8 & 0,6 & 0,2 & 0,8 & & \\
\hline $\mathrm{T} 1$ & $\mathrm{~L}, \mathrm{FI}, \mathrm{A}$ & 43 & 22,8 & 1,9 & 0,35 & 2,25 & & \\
\hline P17 & $\mathrm{L}, \mathrm{FI}$ & 36 & 20,3 & 1,8 & 0,1 & 1,9 & & \\
\hline $\mathrm{P} 10$ & $\mathrm{~L}, \mathrm{~A}$ & 25 & 22 & 2,1 & 0,2 & 2,3 & & \\
\hline P7 & none & 49 & 16,1 & 2,2 & 0,3 & 2,5 & & \\
\hline P5 & none & 39 & 23,6 & 5,5 & 0 & 5,5 & & \\
\hline
\end{tabular}

$\mathrm{L}=$ lubricity, $\mathrm{FI}=$ flow improver, $\mathrm{A}=$ antistatic

Table 2 Fuel oil for test of effect PAH content and of the additive 2-EHN and test results

\begin{tabular}{|c|c|c|c|c|c|c|c|}
\hline \multirow[t]{2}{*}{ fuel } & \multirow{2}{*}{$\begin{array}{l}\begin{array}{c}\text { sulfur } \\
\text { content }\end{array} \\
\mathrm{mg} / \mathrm{kg}\end{array}$} & \multicolumn{4}{|c|}{ PAH content in weight $\%$} & \multicolumn{2}{|c|}{ result of test } \\
\hline & & $\begin{array}{c}\text { mono- } \\
\text { aromatics }\end{array}$ & $\begin{array}{c}\text { di- } \\
\text { aromatics }\end{array}$ & $\begin{array}{c}\text { tri- } \\
\text { aromatics }\end{array}$ & $\begin{array}{l}\text { total poly- } \\
\text { aromatics }\end{array}$ & $\begin{array}{c}\text { yellow flame } \\
\text { burner }\end{array}$ & $\begin{array}{c}\text { blue flame } \\
\text { burner }\end{array}$ \\
\hline $\mathrm{T} 7$ & 15 & 16 & 0,4 & 0,2 & 0,6 & $\begin{array}{l}\text { no MD } \\
\text { in } 75 \mathrm{~h}\end{array}$ & MD \\
\hline light cycle oil S1 & 77 & 54,6 & 21,8 & 8,1 & 29,9 & not tested & not tested \\
\hline $\mathrm{T} 7-30,8 \% \mathrm{~S} 1$ & 34 & 27,6 & 6,9 & 2,6 & 9,5 & $\mathrm{MD}$ in $5 \mathrm{~h}$ & MD \\
\hline $\begin{array}{c}\text { T7-30,8\%S1 } \\
+ \\
1000 \text { ppm 2- } \\
\text { EHN }\end{array}$ & 34 & 27,6 & 6,9 & 2,6 & 9,5 & $\begin{array}{l}\text { no MD } \\
\text { in } 5 \mathrm{~h}\end{array}$ & MD \\
\hline $\begin{array}{c}\mathrm{T} 7-30,8 \% \mathrm{~S} 1 \\
+ \\
500 \mathrm{ppm} 2-\mathrm{EHN}\end{array}$ & 34 & 27,6 & 6,9 & 2,6 & 9,5 & $\begin{array}{c}\text { no } \mathrm{MD} \text { in } 5 \\
\mathrm{~h}\end{array}$ & not tested \\
\hline
\end{tabular}


The area of corroded surface was quantified resulting in the data shown in figure 4 . For pure T5 only small area was affected and for the mixture with sulfur content $500 \mathrm{mg} / \mathrm{kg}$ no corrosion attack was observed. A maximum is found for the sulfur content of 125 $\mathrm{mg} / \mathrm{kg}$. This means that for intermediate concentrations MD is enhances by sulfur. In literature but an inhibiting effect of sulfur has been reported so far.

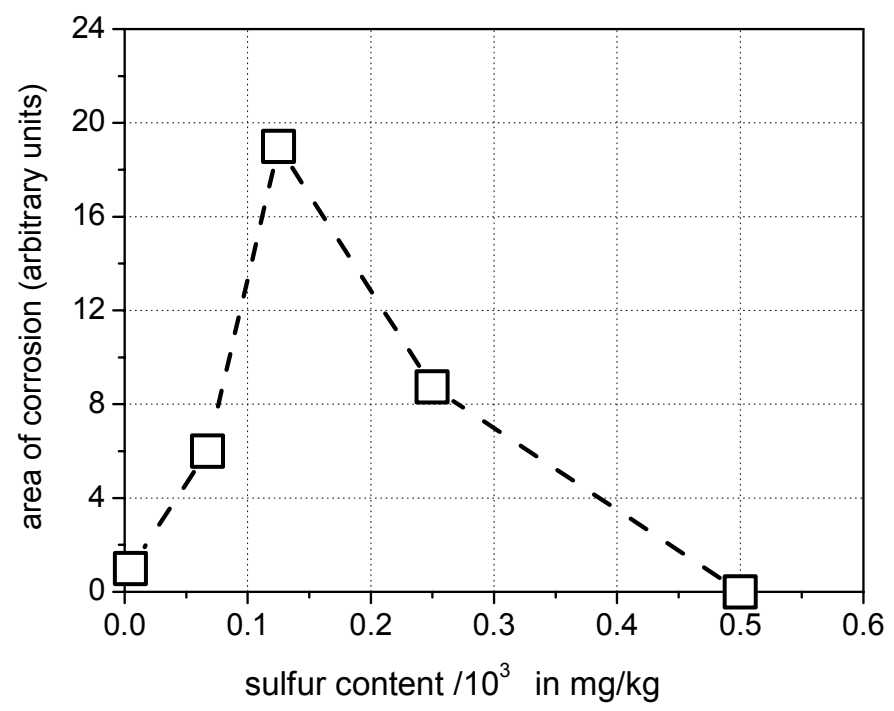

Figure 4.

Area of corrosion attack on the inner tube surface as function of sulfur content of fuel T5

The corresponding investigations of the effect of sulfur content on MD have not jet been performed for the yellow flame burner. According to the authors experience MD is inhibited in the yellow flame burner for sulfur content of two hundred $\mathrm{mg} / \mathrm{kg}$ or more. In the blue flame burner the content of sulfur required for inhibition of MD amounts to the higher value of $500 \mathrm{mg} / \mathrm{kg}$. From the presented experimental results it is concluded that in the blue flame burner the conditions for MD are strongly enhanced. Therefore a discrimination of LSFO as critical or non-critical is not possible by this burner. Also sulfur and additives have to be added in relatively high proportion before any effect sets in. It is assumed that a crucial parameter that causes the different behavior of the two burners is the energy density in the flame tube. For the yellow flame burner this is 84 $\mathrm{W} / \mathrm{cm}^{3}$ and for the blue flame burner it is $108 \mathrm{~W} / \mathrm{cm}^{3}$.

\section{Conclusion}

Combustion of different low sulfur fuel oils in a yellow flame burner showed that the metal dusting tendency is highest for content of di- and tri-aromatics $\geq 2$ weight $\%$ and for intermediate sulfur content of about $20 \mathrm{mg} / \mathrm{kg}$ up to $50 \mathrm{mg} / \mathrm{kg}$. Six low sulfur fuel oils with sulfur content $\leq 15 \mathrm{mg} / \mathrm{kg}$ were not precarious as they did not cause any metal dusting in this burner. The effect of PAHs was confirmed by experiments with a blend of a non-precarious low sulfur fuel oil and a fuel with high content of PAHs. With the 
same blend evidence was found that 2-ethylhexylnitrat suppresses the corrosion enhancing effect of the PAHs.

Test in a blue flame burner gave different results. Tests of two non-precarious LSFOs in resulted in MD. The blue flame burner is equipped with a smaller flame tube. Hence the energy density in the flame tube is higher. It is suggested that due to this in the blue flame burner any low sulfur fuel oil is precarious and high proportions of additive are required to bring about an effect.

By experiments in the blue flame burner evidence was found, that sulfur inhibits MD at high concentrations but enhances MD at intermediate concentrations. This poses new questions concerning the role of sulfur as up to know only an inhibiting effect has been reported in literature.

\section{References}

[1] H. Ackermann, D. Diarra, G. Berger, K Lucka, H. Köhne, W. Brandl, G. Marginean, N. Marginean: 4. Aachener Kolloquium - Heizwärme aus Ölverbrennung, Aachen, September 18 - 19, 17 - 24 (2003).

[2] H. J. Grabke: Materials and Corrosion 54, 736 - 746 (2003).

[3] H.J. Grabke and M. Spiegel: Materials and Corrosion, 54 (2003) 799.

[4] A. Schneider, H. Viefhaus and G. Inden, Materials and Corrosion, 51 (2000) 338.

[5] W. Erley and H. Wagner, Journal of Catalysts, 53 (1978) 287.

[6] K.S. Kim, N.M. Rodrigeuz and T:K. Baker, Journal of Catalysts, 143 (1993) 449.

[7] H.H. Angermann and G. Hörz, Zeitschrift für Metallkunde, 82 (1991) 950.

[8] H. Ackermann, K. Lucka, H. Koehne, L. Lucks, P. Karduck, A. von Richthofen: presentation, Eurocorr 2004 „Long term prediction \& Modelling of Corrosion“, Nice, September 12 - 16, (2004).

[9] H. Ackermann, K. Lucka und H. Köhne: Erdöl, Erdgas, Kohle to be published 
Paper No. 05-04

\title{
Large population remote diagnostic and oil usage system
}

\author{
Richard Simons \\ Honeywell \\ Residential Oil/Hydronic Automation \& Control Solutions \\ MN10-2527 \\ 1985 Douglas Drive North \\ Golden Valley, MN 55422-3992 \\ Phone: 763 954-6761 \\ Fax: 763 954-4440 \\ E-mail: richard.simons@Honeywell.com \\ Internet: www.honeywell.com
}




\section{Large Population Remote Diagnostic and Oil Usage System Rich Simons}

A large endpoint remote diagnostic and oil usage system for residential oil heat systems is described. The business objective for the industry is to reduce operating costs and increase service offerings. The number of residences monitored range from thousands to hundreds of thousands per oil dealer. This paper presents the industry objectives, technology solutions and trade-offs, and field test results.

Voice of the Dealer

Following years of consolidation and alternate fuel competition, oil dealer interviews have yielded a desire to adopt new technology that will allow the industry to remain competitive. To accomplish this in the current energy market the oil industry, like any other business, must continue to decrease its costs while increasing its level of service. Past publications and interviews allow that these objectives can be accomplished by addressing any combination of the following:

- Decreasing fuel delivery costs by increasing the amount of fuel delivery per drop

- Increasing customer retention by reducing dry tanks, no heat calls, and extended service contracts

- Increasing the time between routine maintenance (check-up) calls and thus also decreasing customer dissatisfaction

- Implementing predicative maintenance allowing service to be scheduled during regular hours and reducing overtime pay

- Reducing callbacks by providing additional information to the service technician both prior to the call and at the site

- Implementing additional services such as extended service contracts and home health monitoring

Note that as more of the above services are accomplished more benefit will accrue to the industry. However, different oil dealers will implement different combinations of services depending on their local market and competitive strategy.

The industry has worked with flame quality monitoring for some years now (1) but widespread use has not occurred due to lack of complete "basement to contractor" solution. Recently, equipment run time has been shown as an accurate method for tracking oil usage (2). Thus what is needed is the ability to tie these industry developed technologies together and get the information to the office.

System Overview

There are generally four components needed to construct an end to end system; communications within the residence between the heating appliance and gateway/modem, communications infrastructure between residence and central 
router/server, central router/server, and web based customer interface (see figure 1.) These steps are now described in detail.

Dwelling Communication - The objective of this segment to get data out of the appliance and to a gateway device, such as a modem, for transmission out of the home. An additional objective is to create a system that will allow expansion as future technologies, servicing strategies, and servicing needs are identified.

As oil controls and heating/cooling appliances have transitioned to electronic platforms, their capability has increased dramatically granting them the ability to communicate service-enhancing information to the service technician and additional monitoring devices.

Thus the first activity is to create a communications portal from the oil primary. In this instance a protocol, based on the automotive industry and deployed for several years was chosen for its cost and robustness. This protocol is referred to as EnviraCOM and has been implemented in zoning, thermostats, and telephone access products. This protocol implements a robust multi-drop system that is appliance neutral, allowing common tools and familiarity. The protocol communicates such information as appliance status (idle, running, etc.) and diagnostics as well as control.

It is at this juncture that additional technologies may be brought to market by taking advantage of the expandability of the protocol design. For example data logging devices with or without additional sensors may simply be connected to the bus and intercept data already on the bus, from the oil primary and other devices (thermostats, zoning controls, etc.) Such data logging devices can store data for future presentation (local or remote) and/or forward on messages via the bus for outbound transmission. Thus as future technologies or service strategies evolve, the system can be easily upgraded.

For example, fuel usage is inferred by simply measuring equipment run time. In practice the gateway/modem measures equipment run time, beginning from the last complete oil tank fill. Following the next oil tank fill, the amount of fuel dropped (used) is divided by the accumulated run time, yielding gallons per hour. Equipment run time is then used to measure gallons used and subsequently amount of fuel remaining in the oil tank. This "gallons per hour" factor is recalculated every time the tank is refilled.

For remote access, once data is out of the appliance, it must be communicated out of the house. In the long term, both cellular telephone and mobitex (such as employed by Blackberry devices) technology will come down in costs such as to make it a choice and this is currently supported with the communications infrastructure described below. Until that time the simple land-line telephone will be the system of choice. A gateway/modem is required to perform this function. The gateway receives the EnviraCOM communications and performs such functions as flame quality monitoring, run time accumulation, and dial time control. The gateway/modem would operate to dial out periodically, depending on need, downloading its fuel usage, any flame quality 
information, and updating its real time clock. The gateway/modem would dial out immediately upon lockout detection.

A barrier to the adoption, as detailed in the referenced field test study below, is installation complexity. Specifically, running telephone wires from a phone jack to the appliance may be impossible, difficult, or intimidating. Wireless solutions, developed over time, will reduce or eliminate this barrier.

Communications Infrastructure - There are many methods to communicate data from the residence. These include traditional landline, mobitex (Blackberry), cellular telephone, and Internet (cable or DSL.) Over time some current costs will reduce and new technologies will emerge. The objective of this piece of the system is to accommodate all variety of infrastructure and route incoming data and outgoing presentation on current and future links. This implementation is based on an existing security systems infrastructure that has been put in place to accommodate the needs of both residential and commercial security monitoring and thus has the capacity and cost structure to serve a "many end point" market. In this respect residential security and oil delivery and servicing have much in common.

While it would be possible to route phone based data to a modem bank at an individual contractor site, several downsides exist. This approach would force the installation of a multiple phone line modem at the contractor site, a barrier for many oil dealers. It would also force the customer facing software to run on a local computer, making installation, upgrade, and maintenance difficult and ultimately limiting the adoption of the system. Past implementations of this type have run into difficulties due to area code changes and software upgrade activity. Finally, it would limit the transmission technology to telephone lines.

A centrally maintained router avoids all of these issues. Further it allows inbound (residence) and outbound (customer access or message such as fax, e-mail, or pager) to use technologies as required and available. For example, inbound data could be cellular, cable modem, and telephone line while outbound messaging and presentation could be Internet, e-mail, and fax.

Data Delivery - There are several choices available for the storage and delivery of data to the contractor. Current systems deliver data directly to a contractor based personal computer where a program is installed to for contractor presentation. The downside to this approach is of both installation and maintenance as described above.

A superior approach is to leverage web technology. In this approach the data is stored on a server and accessed by going to a web site and entering a user name and password. Our approach is again to leverage our security infrastructure. Following the router described above is a system that assures data security through authentication and encryption. Data is then stored in a redundant database and referenced by either account address or account number. This is a highly reliable, highly secure system that meets UL and insurance standards for residential and commercial banking security. Another advantage is that it is 
in place now. Finally, individual contractor data may be backed up to a local contractor owned computer if desired.

Customer Facing Software - The final segment is the data deliver to the oil dealer. Once access is obtained by the contractor (user name and password validation), aggregated consumption, run time and pending service data is available. Also available is communications system status and access to individual accounts. When working with individual accounts, oil delivery thresholds and messaging selections (by fax, e-mail, pager, etc.) are configured. See figures 2 through 4.

In operation, a morning report, delivered by e-mail or fax, is generated listing all needed oil delivery and servicing for the coming day. Whenever an account's heating or cooling system shuts down a message report is generated immediately. As fuel is delivered and invoiced, the amount of delivered fuel is entered, resetting the tank level calculation. NORA is sponsoring the development of a data interchange protocol that will allow easy interface to back office software programs. This linkage could share data such as fuel drop size for both billing and fuel usage calibration, service account number and street address, service needs and billing invoicing.

\section{Field Test Results}

During the 2004 winter twenty sites via four oil dealers were deployed. The results of this test yielded valuable information concerning installation, system usage, and navigation. Installation was carried out by a combination of a trained gateway/modem installed and local service technician. Installation consisted of 1) replacing the existing oil primary with a standard communicating oil primary, 2) connecting the gateway/modem to power source and telephone, 3) wiring thermostat type wire between the oil primary, and 4) programming the gateway/modem. Typical installation required about 1 hour. As expected the most difficult obstacle occurred with the running wire between the oil primary and gateway/modem as phone jacks may not be available near the HVAC appliance. Discussions with the service technicians yielded the need to eliminate any gateway/modem programming but a general comfort with connecting the systems. A need for confirming communications link was also identified.

System effectiveness can be discussed from both service events and oil delivery accuracy. Of the 20 installed home sites, there were a total of 5 service events that were detected during the test. These are detailed in table 1 .

\begin{tabular}{|l|l|}
\hline Reason & $\begin{array}{l}\text { Number } \\
\text { of Events }\end{array}$ \\
\hline Bad ignition transformer & 2 \\
\hline Replaced nozzle & 1 \\
\hline Sludge & 1 \\
\hline Replaced various components & 1 \\
\hline
\end{tabular}

Table 1 - Reason for service events 
The first event was detected within one week of the system being installed. In this case a fuel delivery was made, stirring up sludge in the tank and causing a primary lockout. The information was dispatched to the oil dealer who contacted the homeowner informing them of a service dispatch. A service technician arrived at the site shortly thereafter and restored the system prior to the homeowner being aware that anything was amiss.

The participating oil dealers used the field test to gain comfort with the fuel usage capability, comparing it to the amount of fuel that was dropped using existing methods of prediction. The one oil dealer interviewed indicated that the predicted results tracked actual drops within 5 gallons, confirming previous work in this field.

All participating oil dealers were interviewed on their usage and navigation of the website. When service event occurred several of the dealers would use the site to view historical operating data such as flame readings. Initially all gained familiarity with the site and demonstrated the ability to navigate and access features. Once the reports were set up, the site became less used, unless service events occurred, as users simply relied on the reports to be sent as needed.

Some of the participants noted the ability to observe individual account fuel usage during summer and winter, as well as graphically monitor peaks which yielded insight into service or delivery needs. Additional report delivery modes, such as Blackberry and cell phone were noted. All participating oil dealers indicated a desire to further deploy the technology.

\section{Next Steps}

Post field test interviews uncovered a number of additional features that are desired. These include the additional means to measure equipment usage since the last service date to allow minimum and maximum service interval notification. As previously discussed, interface to back office systems is needed and is being sponsored by NORA.

Simplification of installation is desired with a wireless connection between HVAC equipment and gateway/modem located at the telephone jack. Clearly, as different oil dealers employ newer communications technologies, their accommodation must be employed.

\section{Conclusions}

The implementation of the above-described system begins to provide the oil industry with some of the tools that allow it to remain competitive in the energy sector. In this respect the oil industry, once though to be slow to change, is at the same pace as other energy sectors in adopting new technology. Oil delivery efficiency can be improved and predictive maintenance used to reduce costs and increase levels of service. In addition to using flame quality monitoring and fuel usage functions, all field test users noted that the ability to better service their customers by solving any problems before they are detected as a key advantage. 


\section{References}

(1) Flame Quality Monitoring - Numerous reports have been presented at BNL Oil Technology Conferences under the guidance of Tom Butcher. These include:

BNL 52250, "Performance Control Strategies for Oil-Fired Residential Heating Systems.” July 1990

BNL-61860, "Flame Quality Indicator for Oil-Fired Applications.” September 1994.

Development and Technology Transfer of the BNL

(2) Fuel Usage - During the winter of 2002/3 a team of companies, including BNL, Honeywell, and Insight Technologies implemented a field test that combined Flame Quality Monitoring, Fuel Usage, and basement to central monitoring communications. The results of this were published as a DOE topical report: Butcher, T., Rudin, A., and Troost, H. "Field Test of the Flame Quality Monitor", project report submitted to the National Energy Technology Laboratory, U.S. Department of Energy, February, 2003. The fuel usage strategy was proven to be accurate to within a few gallons and the flame quality monitoring strategy was again confirmed.

Figure 1 - Key Components for "basement to office" communications

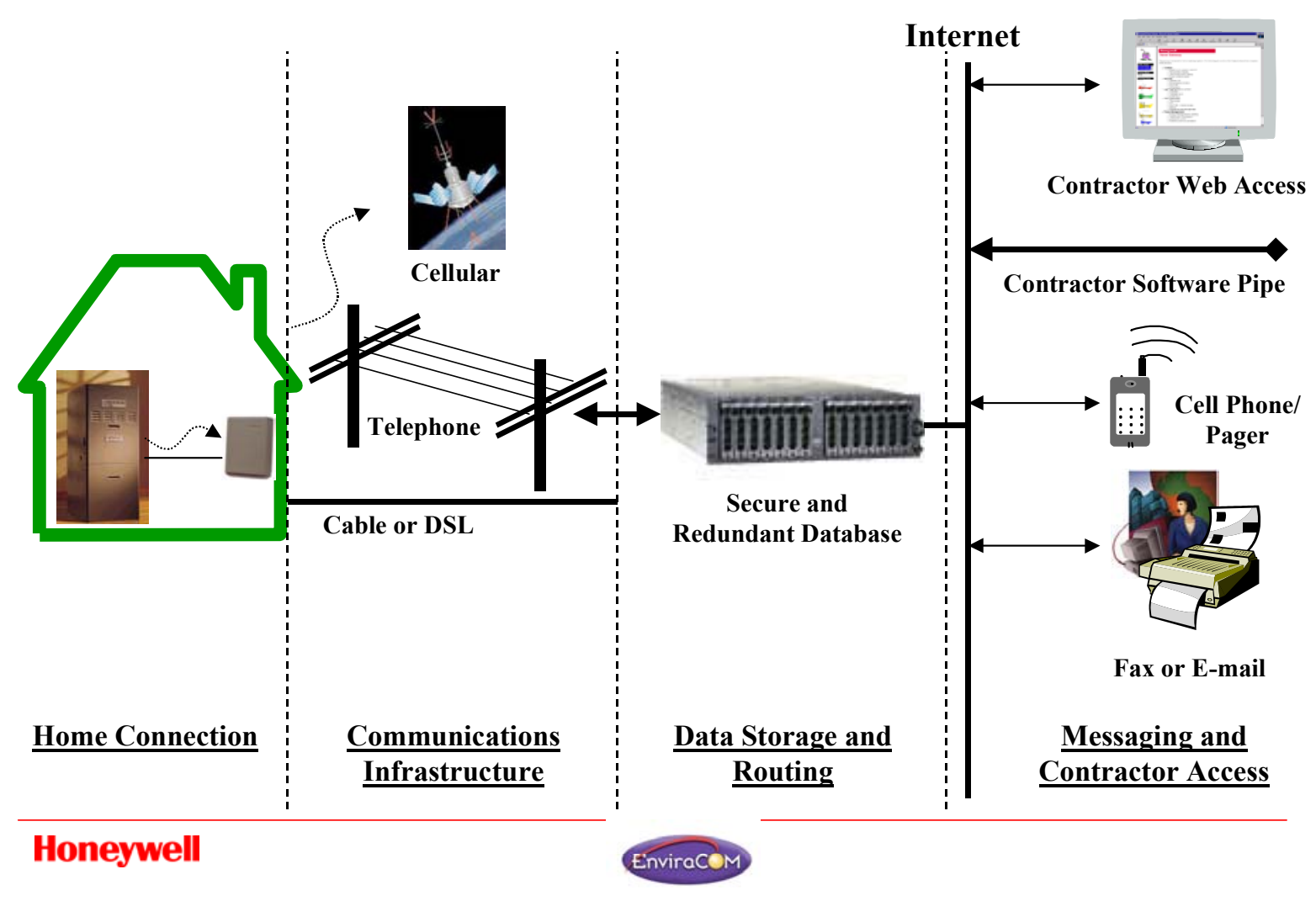


Figure 2 - Report Set-up

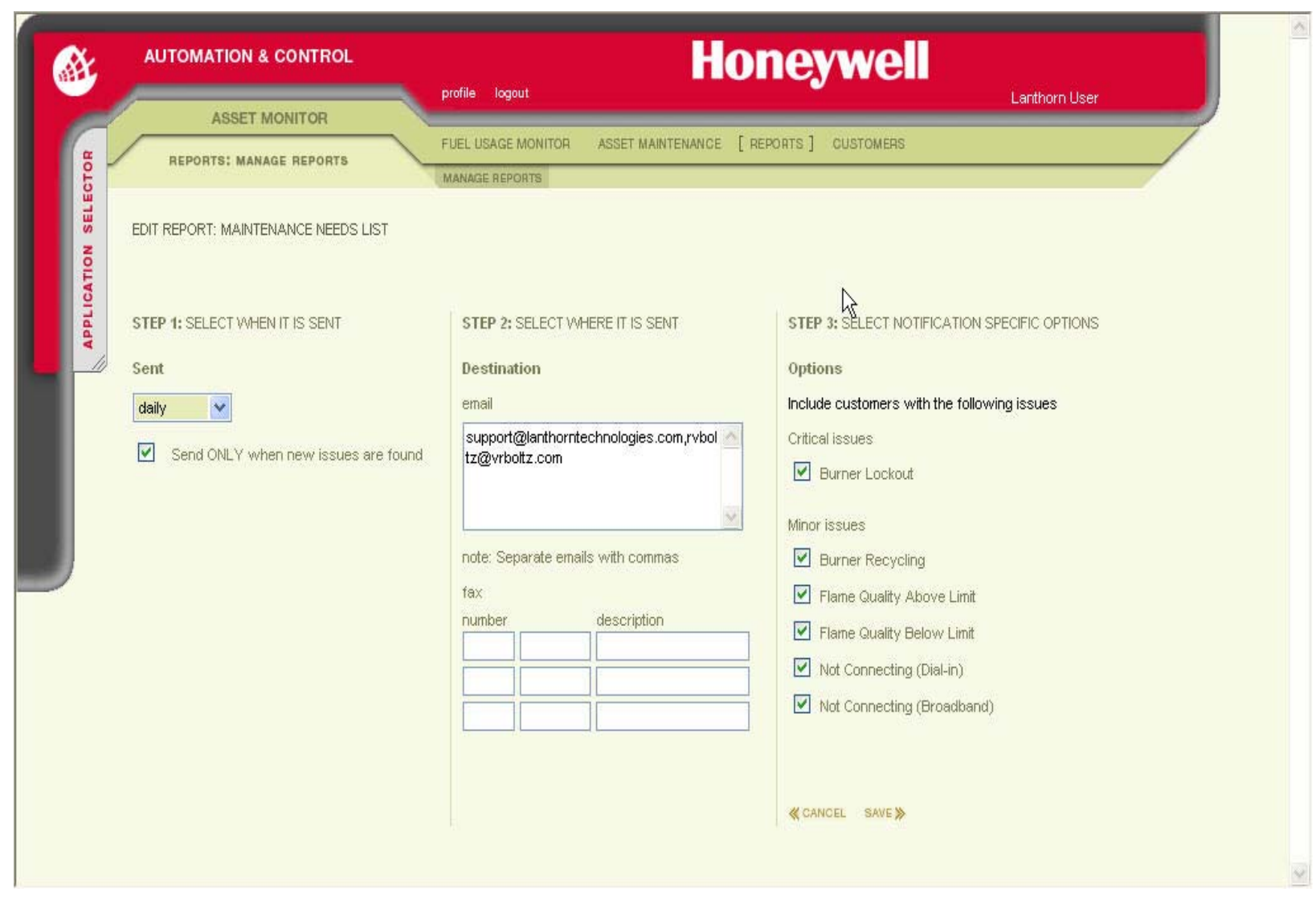

Figure 3 - Equipment Overview

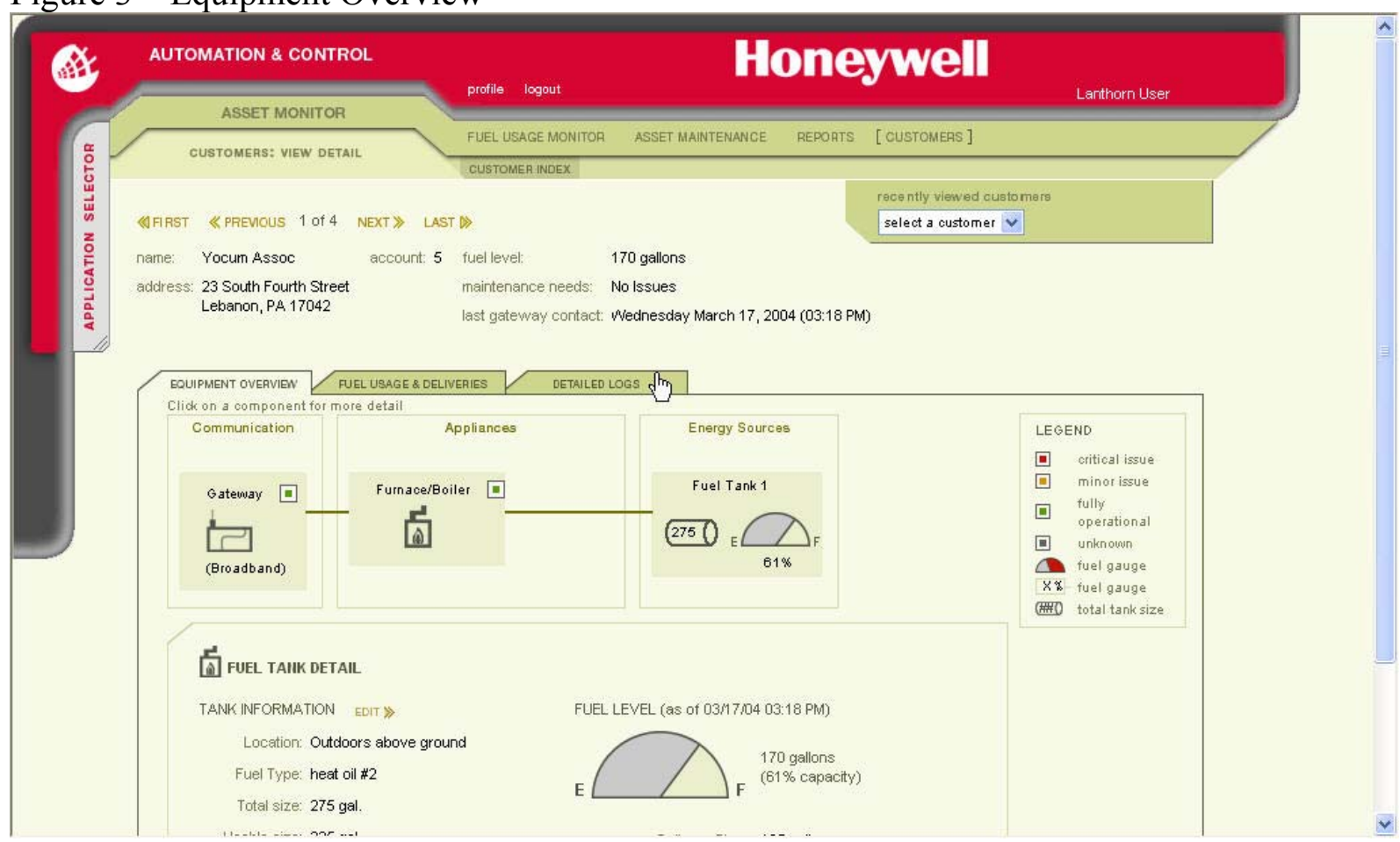


Figure 3 (continued) - Detail Maintenance Log

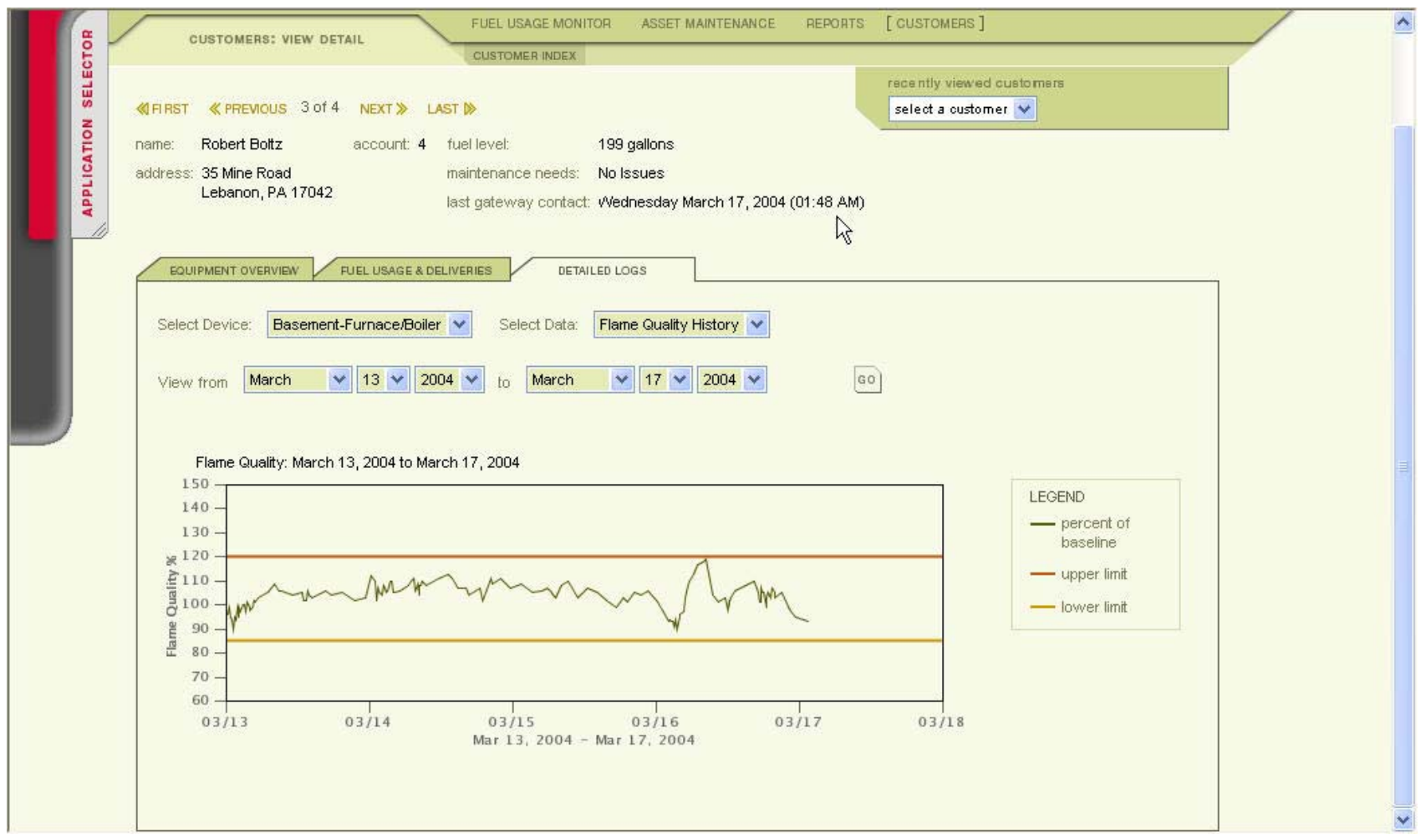




\title{
Paper No. 06-04
}

\section{Evaluation of soybean heating oil blends for use in residential applications}

\author{
Nicholas W. Vanlaningham \\ Harry G. Gibson \\ Bradley G. Kaufman \\ Purdue University \\ Agricultural and Biological Engineering \\ 225 South University \\ West Lafayette, IN 470907 \\ Phone: 765 494-1190 \\ E-mail: vanlannw_abe@alumni.purdue.edu \\ E-mail: gibson@ecn.purdue.edu \\ E-mail: kaufmabg@purdue.edu \\ Internet: www.purdue.edu
}




\title{
Evaluation of Soybean Heating Oil Blends for Use in Residential Applications \\ Nicholas W. Vanlaningham, Professor Harry G. Gibson and Bradley G. Kaufman Purdue University
}

\begin{abstract}
Soybean heating oil (SHO) has great potential to become a renewable component in residential heating applications. Research at Purdue University has demonstrated SHO20, 20\% degummed soybean oil and $80 \%$ petroleum fuel, to be comparable to $\# 2$ petroleum fuel oil. The kinematic viscosity of SHO20, 3.46 cSt at $100^{\circ} \mathrm{F}\left(37.8^{\circ} \mathrm{C}\right)$, was within the ASTM requirement for petroleum fuel oil. The net heating value of SHO20 was only $1-3 \%$ lower than pure petroleum fuel oil on a volume basis. Nitric oxide emissions at optimal furnace settings were similar for fuel oil and SHO20 with values between $68 \mathrm{ppm}$ and $130 \mathrm{ppm}$.

Benefits of SHO include reduced dependence on foreign oil and a new market for the soybean processing industry. Replacing just one quarter of the northeastern United States residential fuel oil consumption with a $20 \%$ soybean heating oil blend would utilize nearly 5.7 million acres of soybeans. This mixture also reduces the amount of carbon introduced into the carbon cycle.
\end{abstract}

\section{Introduction}

Liquid fuel containing renewable components is not a new concept. However, only recently have products like biodiesel and ethanol become widespread in the United States. As the worldwide demand and price for energy increases, the move towards more renewable fuels will also increase. Soybean oil as an additive to fuel oil makes an important contribution to the security and energy balance of the United States. Soybean heating oil (SHO) has significant potential to decrease our dependence on foreign oil. The renewable soybean oil component also frees up valuable petroleum resources for products that have no alternative source, and when burned do not contribute carbon into the world cycle (as does petroleum).

SHO is a combination of petroleum fuel oil and renewable soybean oil. Oils specific to this analysis are \#2 petroleum fuel oil and degummed soybean oil. The petroleum fuel oil is considered a middle distillate fuel related to diesel and kerosene fuels. Degummed soybean oil is slightly refined to remove hydrated phosphatides found in crude oil. This stabilizes the oil for storage, transportation, further processing and/or lecithin recovery (Hui 1996).

In 2001, the United States used a total of 6.6 billion gallons of petroleum fuel oil in residential heating applications. The northeast region was by far the largest consumer with nearly 5.8 billion gallons (DOEEIA). If one quarter of the total northeast consumption were replaced with a $20 \%$ soybean oil blend, 290 million gallons of soybean oil would be required. This would represent about $10 \%$ of the 3 billion gallons of soybean oil produced in 2002 , or about $8 \%$ of the 72 million acres of soybean production (USDA). The impact on the agricultural and oil production industries would be tremendous if SHO were commercialized.

SHO has great potential to assist the oilheat industry meet goals recently adopted in the Oilheat Industry Roadmap. Renewable "green" fuels can be marketed to consumers in an attempt to increase conversions and new home installations.

\section{Materials and Methods}

The primary objectives were met through the completion of several smaller projects related to each objective. Blends from pure fuel oil to pure soybean oil were analyzed for characteristics beneficial to residential heating applications. Laboratory combustion tests using various fuel blends and furnace settings were performed using a residential type furnace. Finally, field tests using $10 \%, 20 \%$ and $30 \%$ $\mathrm{SHO}$ blends were also implemented. A maximum blend ratio was determined after analyzing the test 
data. The ratio is the upper limit recommended for residential heating applications which avoids problems due to incompatible fuels.

Soybean heating oil blends for this project were mixed using a splash blending technique. This method poured the denser soybean oil into a container which initially held only the petroleum fuel oil. The resulting blend was designated SHOxx where the ' $\mathrm{xx}$ ' specified the percentage of degummed soybean oil. No special chemicals or additives were used to maintain the mixtures. Blends did not show signs of stratification but cake deposits and thin films were noted in some SHO blends after one year of storage.

\section{Soybean Heating Oil Characteristics}

According to the National Oilheat Research Alliance (NORA) residential heating oil provides consumers with dependable, "better quality" heat compared to natural gas or electric heat. Any modification to the current heating oil supply should maintain if not improve the current image presented by NORA and its member companies. Soybean oil should be looked at as an additive as opposed to a $100 \%$ replacement for petroleum fuel oil. A maximum SHO blend was determined based on cold temperature properties, net heating value, and overall blend quality.

\section{Temperature Points}

Cold weather fuel properties are important in fuel oil due to its use during winter months. These properties are important primarily in outdoor storage and also during transportation. Fuel delivery lines, especially in residences with outdoor storage tanks, are very susceptible to cold weather problems due to their small diameter.

Cloud point is defined as the temperature where wax crystals begin to form and precipitate from the fuel oil (Williams 1989). The wax crystals may settle to the tank bottom or clog filters, nozzles or strainers during operation. In general, the actual cloud point temperature differs depending on the rate of cooling and chemical make up. It is typically $10^{\circ} \mathrm{F}\left(-12.2^{\circ} \mathrm{C}\right)$ to $20^{\circ} \mathrm{F}\left(-6.6^{\circ} \mathrm{C}\right)$ above the pour point. Cloud point values are difficult to establish in vegetable oils such as soybean oil due to the wide variation in triglyceride composition between different varieties of soybeans.

Pour point indicates the lowest temperature at which the fuel oil in the system can still flow. It is $5^{\circ} \mathrm{F}$ $\left(3^{\circ} \mathrm{C}\right)$ above the temperature where the oil solidifies (Williams 1989). At or below the pour point, the gelled fuel can not flow through supply lines and therefore reach the heating equipment. Although the ASTM standard for No. 2 oil is $20^{\circ} \mathrm{F}\left(-6.7^{\circ} \mathrm{C}\right)$, the pour point temperature of fuel sold to consumers can typically range from $0^{\circ} \mathrm{F}\left(-17.7^{\circ} \mathrm{C}\right)$ to $-55^{\circ} \mathrm{F}\left(-48.3^{\circ} \mathrm{C}\right)($ Hedden 2003$)$.

The flash point, primarily a safety concern, is the maximum temperature where enough fuel vapor is present to momentarily ignite but not enough to cause continuous burning (Boone 1952). This is the point where the fuel is beginning to ignite but still cannot support a flame. An external flame is passed over the hot fuel until flashes of burning fuel appear (Hui 1996). Erickson (1980) reported flash points of $565^{\circ} \mathrm{F}\left(296^{\circ} \mathrm{C}\right)$ for crude expeller pressed oil and $625^{\circ} \mathrm{F}\left(329^{\circ} \mathrm{C}\right)$ for refined and bleached oil. Fuel oil had multiple values of $130^{\circ} \mathrm{F}\left(54.4^{\circ} \mathrm{C}\right)$ and $214^{\circ} \mathrm{F}\left(101.1^{\circ} \mathrm{C}\right)$ reported (Hedden 2003$)$.

A certified lab performed temperature point analyzes on four different fuel blends. Fuel oil was tested to obtain a baseline while $20 \%, 50 \%$ and $100 \%$ soybean oil fuels were tested in duplicate. The value for both blend samples were averaged and reported.

\section{Heat Content}

Fuel oil is used in steam, hot water, and forced air heating equipment to heat residences. Therefore, the heat of combustion of the fuel is very important in space heating applications. When economic and emissions factors are equal, the fuel with the highest heat energy content is the most valuable. High 
energy fuels can produce more heat per both dollar and emission unit then lower heat content fuels. The net heat of combustion can be determined accurately and directly using a bomb calorimeter or indirectly using equations based on the iodine and saponification values.

Heat energy of fuel samples were measured directly using a bomb calorimeter. ASTM D 4809, Standard Test Method for Heat of Combustion of Liquid Hydrocarbon Fuels by Bomb Calorimeter (Precision Method), provided basic guidelines for performing the analysis. Blend ratios using crude and degummed soybean oil as well as soy methyl esters were analyzed using the bomb calorimeter.

\section{Viscosity}

Viscosity is a measure of resistance of a liquid to flow. It is significant to both pumping of the fuel oil and the atomization process in the burner. Viscosity can be determined experimentally or through experimental relationships derived by other researchers. Gunstone (2002) discussed the linear effect longer fatty acid chains have on viscosity and the rate of change in viscosity in vegetable oils. The higher degree of saturation leads to more viscous oil and a faster change in viscosity. This means soybean oil with a large fraction of the poly-saturated linoleic acid should be higher in viscosity compared to palm oil with a larger fraction of oleic acid. Fernando (2001) reported more general equations related to the different grades of soybean oil. Both crude and degummed soybean oil showed similar viscosity characteristics while methyl soyate showed smaller kinematic viscosity values over the same range.

A certified lab performed viscosity analysis at $100^{\circ} \mathrm{F}\left(37.8^{\circ} \mathrm{C}\right)$ on four different fuel blends. Fuel oil was tested to obtain a baseline while $20 \%, 50 \%$ and $100 \%$ soybean oil fuels were tested in duplicate. The values for both blend samples were averaged.

\section{Furnace Combustion Tests}

Researchers from well known organizations have recently been performing combustion tests on bio-based heating fuels. Brookhaven National Lab (BNL), New England Fuel Institute (NEFI), CANMET Energy Technology Centre (CETC) and RW Beckett Corporation all lead current research into heating oil containing renewable heating oil components. The majority of the research performed at these organizations focuses on biofuel (crude soy methyl esters) or commercially available biodiesel blends. Both high sulfur (HS) and low sulfur (LS) fuel are used as the base for the blends. The primary reason for focus on LS is the direction of the transportation industry which currently uses diesel fuel with low sulfur content at $500 \mathrm{ppm}$.

All researchers testing renewable components in heating oil used at least $20 \%$ blends during combustion tests. Oilheat researchers categorized vegetable oils and their unrefined methyl ester derivatives as biofuels. The commercially available refined methyl esters were considered biodiesel by the researchers.

\section{Laboratory Equipment}

A forced air furnace similar to the one shown in figure 1 was used in this research. The high boy design has the heat exchanger stacked on the combustion chamber with flue and warm air outlets on top.

The burner unit controlled the fuel flow, combustion air flow and flame ignition. It contained electronic controls, a gear type fuel pump, a combustion air blower, and an excess air control. The pump and blower were directly driven by an electric motor.

A combustion analyzer was used to measure $\mathrm{NO}, \mathrm{NO}_{2}, \mathrm{O}_{2}, \mathrm{CO}$, and $\mathrm{SO}_{2}$ concentrations in flue gas with an accuracy of 20ppm. A built-in sampling pump drew the flue gas through a condensation trap and a particle filter and then into the sensor chamber. The flue gas temperature was measured with an integrated thermocouple. 
Volumetric flow of the fuel was measured using a $50 \mathrm{ml}$ burette and a stopwatch. The burette was inline with the fuel delivery system between the filter and the burner pump. During flow rate measurements, a valve at the filter was closed and the burette stopcock was fully opened. The stopwatch measured the time it took for the furnace to consume a specified volume, typically greater then $10 \mathrm{ml}$. The results were recorded and then converted to gallons per hour.

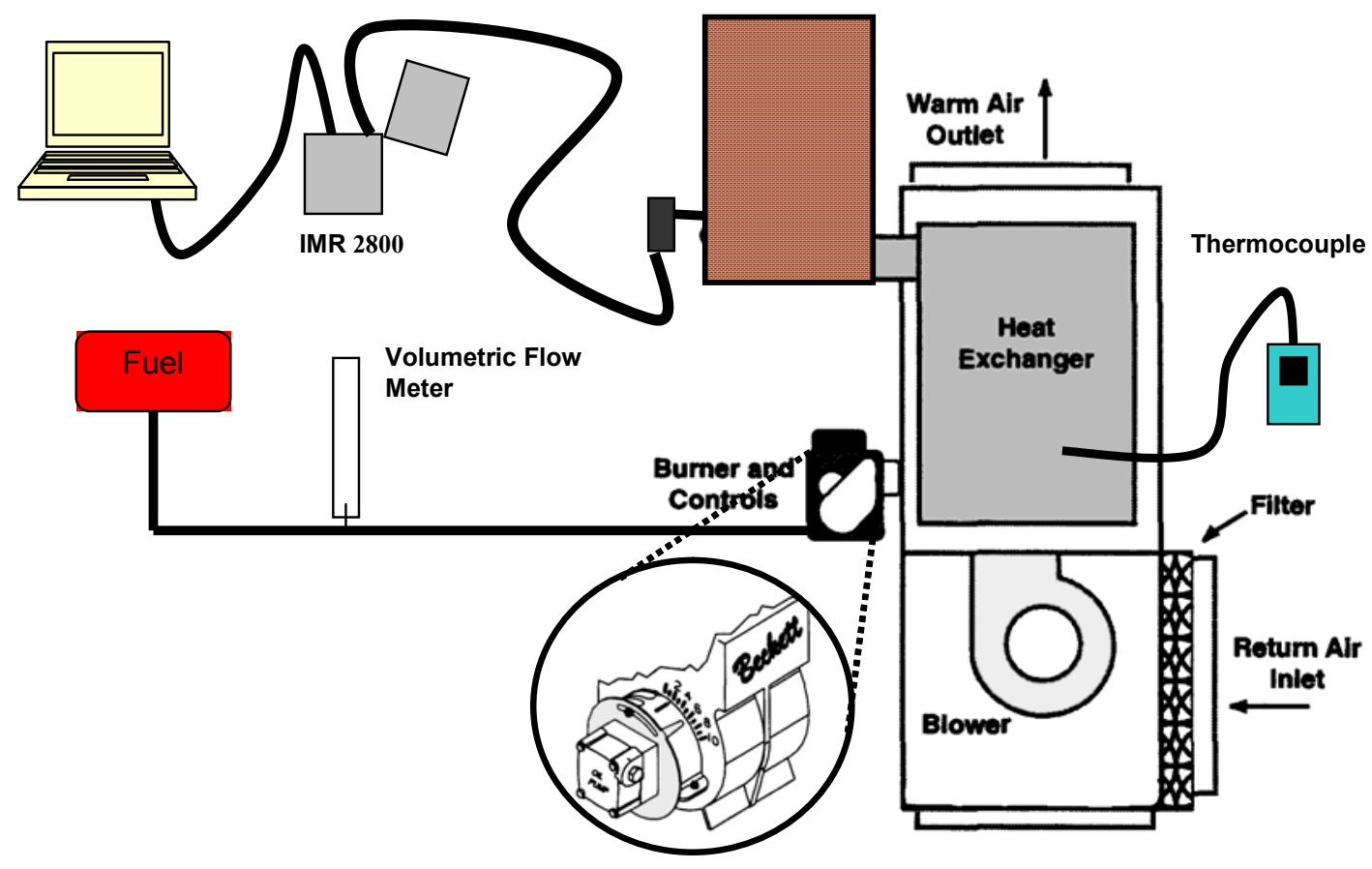

Figure 1 Purdue laboratory equipment setup

A smoke gun was used to obtain the "smoke spot number" from the flue exhaust. ASTM standards D 2156-94 and D 2157-94 were referenced in this data collection procedure. The operation is similar to a bicycle tire pump except that this device pulls a vacuum instead of pumping air. The resulting spot is then compared to a standard chart with color ratings from 0 to 9 . A zero number is best in terms of low to no smoke production while a 9 is an indication of poor combustion quality. The smoke results are plotted versus $\mathrm{O}_{2}$ emissions to assist in the combustion emissions analysis and optimization.

Furnace Optimization

\begin{tabular}{cccc}
\hline Fuel Type & $\begin{array}{c}\text { Pump Pressure } \\
\mathrm{psi}\end{array}$ & $\begin{array}{c}\text { Nozzle Type } \\
\text { GPH x Spray Angle }\end{array}$ & Air Shutter Setting \\
\hline Fuel Oil & 100 & $0.60 \times 80^{\circ}$ & \\
SHO20 & 130 & $0.75 \times 80^{\circ}$ & $0-10$ \\
SHO50 & 160 & $0.85 \times 80^{\circ}$ & \\
\hline
\end{tabular}

Table 1 Controlled Factors

Steady state combustion emissions were collected for 27 different controlled operating conditions. The fuel, nozzle and pump pressure combination was held constant while the air shutter value was varied. Table 1 lists the controlled furnace system settings used during laboratory combustion tests. At least two separate laboratory tests for each fuel and nozzle configuration were performed on different days. 
One test, for example, used $\mathrm{SHO} 20$ with a $0.60 \times 80^{\circ}$ nozzle. The system pressure was changed to one of the three pressures listed. The air shutter value would be adjusted to 4-5 positions and the furnace would be allowed to reach steady state. This resulted in over 12 steady state data sets for the fuel and nozzle combination.

The furnace optimization chart in figure 2 plots the $\mathrm{O}_{2}$ emissions versus the Bachrach smoke spot number, $\mathrm{NOx}, \mathrm{SO}_{2}$, and $\mathrm{CO}$ emissions for different air shutter settings. The air shutter value increases when moving from left to right on the $\mathrm{x}$-axis. This means that more air is available for combustion which is indicated by an increase in flue oxygen. The optimal combustion point is defined as the $\mathrm{O}_{2}$ value immediately to the right of the smoke number zero point. This is where the furnace is most efficient, meaning the excess air is minimized to the point where flue heat losses are minimized but complete combustion still occurs. For this research, the range from the optimal point plus $0.5 \%$ was used to determine gas emissions.

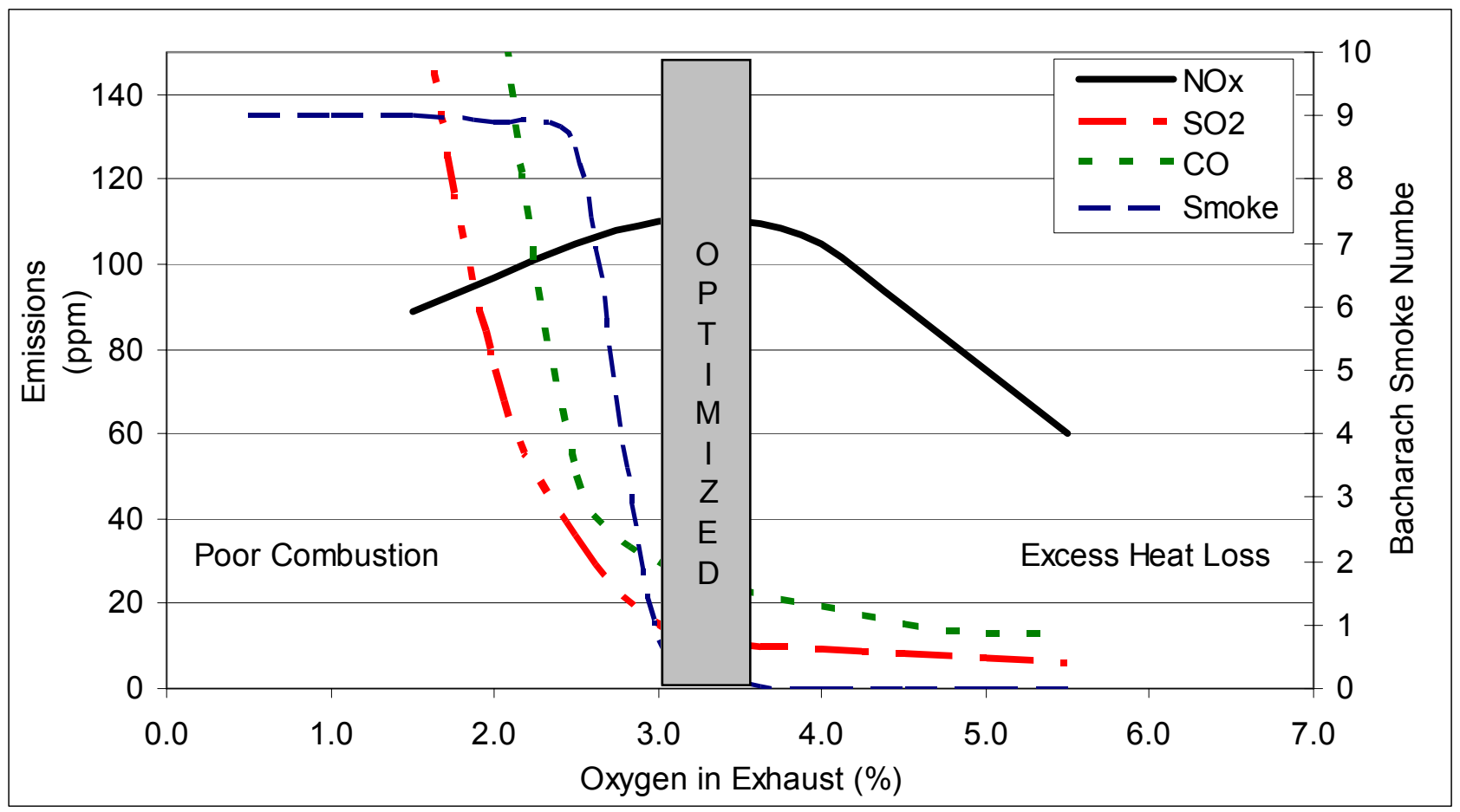

Figure 2 Example combustion optimization curve

The flue gas emissions were plotted against $\mathrm{O}_{2}$ and then the optimal operating range for the fuel, nozzle, and pressure combination is overlaid. Figure 2 is an example of an optimized emissions curve. The range of emission values for each flue gas was determined through visual inspection of the chart. The optimized values for this chart were $110 \mathrm{ppm}$ for $\mathrm{NOx}$ and $10-15 \mathrm{ppm}$ for $\mathrm{SO}_{2}$. These results were combined with other system combinations for emissions comparison.

The minimum optimized $\mathrm{O}_{2}$ emission was used to determine other optimized steady state emissions. For example, if the optimized $\mathrm{O}_{2}$ value was $3 \%$ as in figure 2 , then $0.5 \%$ was added to the value to create an optimized range. This range represented the excess air levels required for proper combustion without excess heat losses. $\mathrm{NOx}, \mathrm{SO}_{2}$ and net flue gas temperatures within this range (3-3.5\%) were averaged to determine the steady state emissions for the particular furnace system setup 


\section{Field Tests}

Short term

Two SHO blends containing degummed soybean oil and petroleum fuel oil were used in this test. Blends were stored in 55 gallon drums to prevent problems with the permanent fuel systems. A $10 \%$ blend was used for the client \#1 residence which required outdoor storage. The client \#2 residence burned a 30\% blend and utilized indoor storage. Both furnaces were inspected and cleaned by oilheat technicians prior to the initial test date. The technician replaced both the fuel filter and nozzle, cleaned the heat exchanger, and adjusted the furnace for optimal combustion.

Several measurements were taken periodically during this short term field test. The weather conditions around Lafayette were recorded daily. Fuel levels were watched by the homeowners with official data recorded by research team members.

\section{Results and Discussion}

\section{Soybean Heating Oil Characteristics}

The results of this research indicate SHO blends with less then $20 \%$ degummed soybean oil have characteristics similar to petroleum fuel oil. BNL researchers recently suggested that for boiler applications not all ASTM biodiesel requirements were needed for "off-spec" fuel blends containing biofuel (Krishna 2003). This could potentially lead to lower fuel costs for biofuel blends by eliminating unnecessary refining steps.

\section{Temperature Points}

The cold temperature points for both SHO20 and SHO50 were well below freezing. Figure 3 indicates the pour point for $\mathrm{SHO} 20$ was near $-22^{\circ} \mathrm{F}\left(-30^{\circ} \mathrm{C}\right)$ with the cloud point at $-17^{\circ} \mathrm{F}\left(-27^{\circ} \mathrm{C}\right)$, while the pour point for the baseline fuel was $-20^{\circ} \mathrm{F}\left(-29^{\circ} \mathrm{C}\right)$ with the cloud point at $9^{\circ} \mathrm{F}\left(-12.8^{\circ} \mathrm{C}\right)$. There was a linear increase in these values as the soybean ratio increased.

Cold flow problems in outside storage tanks can be alleviated by adding No. 1 fuel oil, kerosene or pour point depressants to the fuel tank, and by moving the fuel filter to a temperature controlled environment (Hedden 2003). The flow properties will also improve if the fuel temperature is increased to a point above the cloud and pour points.

Figure 4 shows the measured flash point values for the SHO blends along with the baseline fuel. Both SHO20 and SHO 50 were within the recommended fuel oil range. However, SHO50 blend had difficulty igniting during cold start situations. The longer carbon chains and unsaturation of vegetable oil account for the higher flash point ("Energy" 1999). Lower flash point fuel such as gasoline will be more likely to ignite when exposed to a flame as compared to middle distillate fuels. Although vegetable oils are safer to handle, the high flash points can increase deposits on igniters and combustion chambers in industrial boilers with frequent starts and stops ("Energy" 1999). 


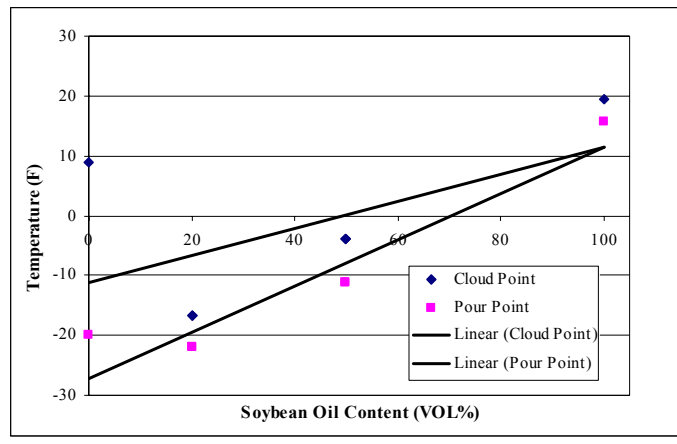

Figure 3 Cloud and Pour Points for SHO

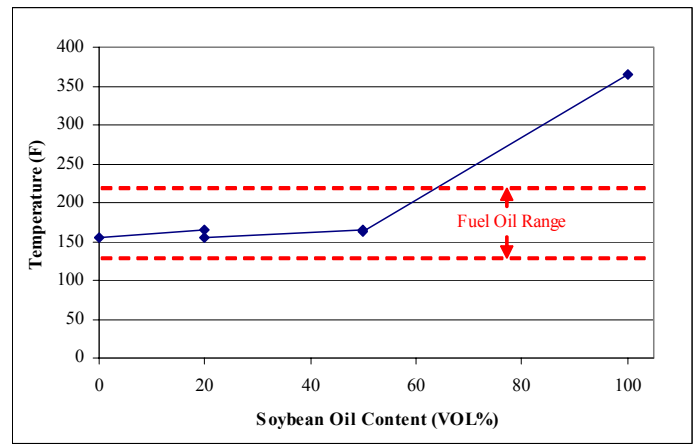

Figure 4 Flash Point for SHO

\section{Heat Content}

Heating oil distributors sell fuel oil to customers on a volume basis. Thus, it is beneficial to report heating values in the form of heat energy per unit volume. The heat value affects the specific fuel consumption of a fuel. Soybean oil has a 15-20\% lower heating value than petroleum fuel oil ("Energy" 1999). Hiler (1985) reports that soybean oil has $10 \%$ lower heating value than petroleum fuel oil. When the values in table 2 are considered, soybean oil has $12.5 \%$ less heat energy available on a volume basis. All this indicates that a larger volume of vegetable oil is required to meet the same energy level of fuel oil. Thus, vegetable oil has higher specific fuel consumption.

Table 2 Net Heat Content of SHO and its components

\begin{tabular}{ccc}
\hline Ratio & SHO w/ Degummed Oil & SHO w/ Crude Oil \\
\hline & BTU/gal (MJ/L) & BTU/gal (MJ/L) \\
\hline 0 & $139167(38765)$ & $139167(38765)$ \\
\hline 20 & $135490(37741)$ & $138046(38453)$ \\
\hline 50 & $132442(36892)$ & $133799(37270)$ \\
\hline 100 & $127631(35552)$ & $129268(36008)$ \\
\hline
\end{tabular}

Viscosity

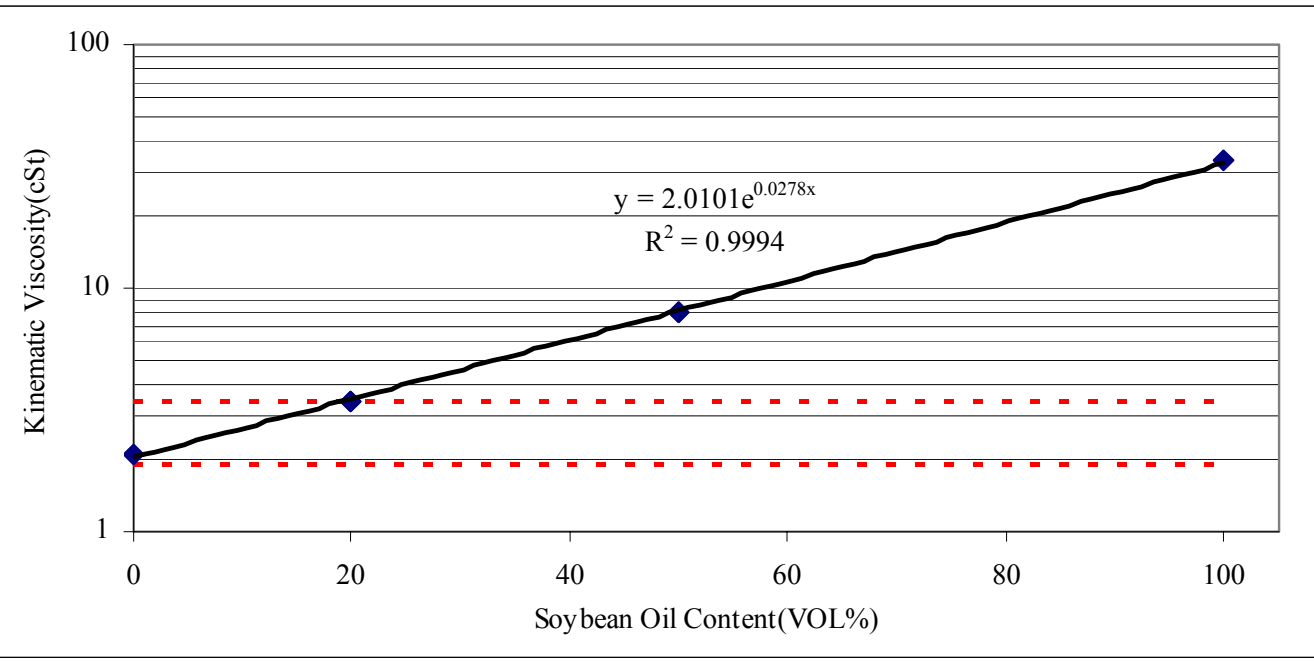

Figure 5 SHO kinematic viscosity at $100^{\circ} \mathrm{F}\left(37.8^{\circ} \mathrm{C}\right)$ as determined using ASTM D 445 
The kinematic viscosity at $100^{\circ} \mathrm{F}\left(37.8^{\circ} \mathrm{C}\right)$ for soybean heating oil at different blends was also measured by Intertek Caleb Brett. The SHO blend results and ASTM recommended range represented by the dashed lines are shown in Figure 5. The measured viscosity of pure degummed soybean oil was 33.20 cSt while the value predicted by Fernando (2001) was $30.33 \mathrm{cSt}$. There was a $76 \%$ decrease in kinematic viscosity from measured value for pure soybean oil to the $50 \%$ blend. The $20 \%$ degummed soybean oil blend had an $89.6 \%$ lower viscosity when compared to pure soybean oil and $56.6 \%$ lower viscosity compared to SHO50. The kinematic viscosity of the SHO20 blend was $3.46 \mathrm{cSt}$ which is within the ASTM recommendation for petroleum fuel oil.

\section{Field Tests}

The client \#1 residence became the first known user of soybean heating oil on March 7, 2003. SHO10 was prepared in two 55 gallon drums for the short term test but a single drum lasted through April 2003. There were no problems directly related to the soybean heating oil blends.

The client \#2 residence began using SHO30 on March 11, 2003. Two 55 gallon drums were prepared for the house and both were consumed within 44 days of the start date. There were two problems with the furnace performance during this time period. The first related to the initial drum running out of fuel. The second call related to the failure of the furnace to fire. After inspecting the furnace, pump failure was determined to be the problem. The drive shaft had rounded at the keyway. A new pump was installed and the test continued without any more problems.

Combustion Tests

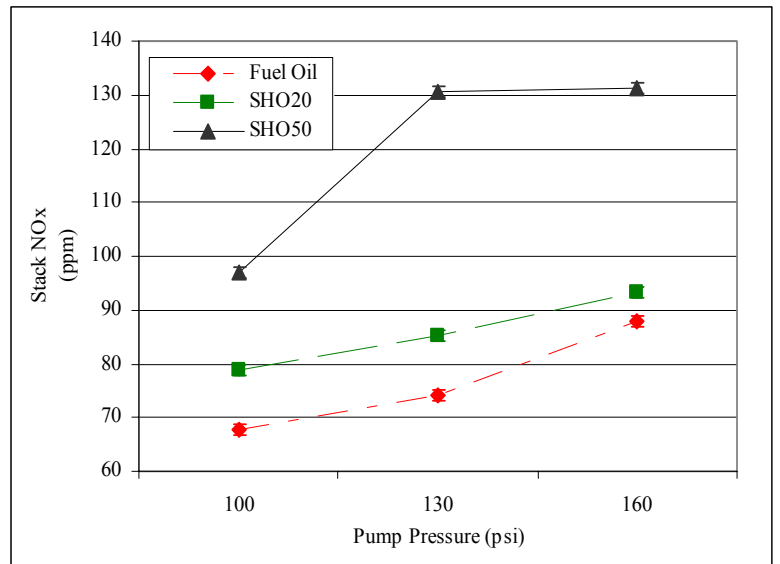

Figure 6 NOx emissions for the $0.60 \times 80^{\circ}$ nozzle

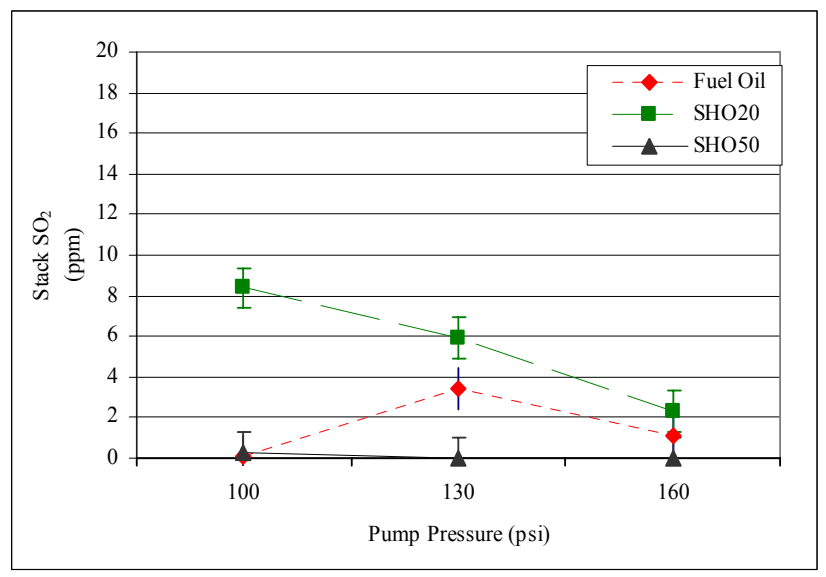

Figure $7 \mathrm{SO}_{2}$ emissions for the $0.60 \times 80^{\circ}$ nozzle

Optimized emissions were measured for many fuel, nozzle, and pressure settings. The $0.60 \times 80^{\circ}$ nozzle data presented in Figure 6 and Figure 7 are representative of all the combinations. The NOx emissions showed a general increase with pressure. When the analyzer's accuracy of $20 \mathrm{ppm}$ was considered, a difference in emissions between fuel oil and SHO20 can not be established. The SHO50 values were significantly higher when a 95\% confidence interval was considered.

The average optimized $\mathrm{SO}_{2}$ emissions showed a general decrease with increased pressure. SHO50 produced virtually zero $\mathrm{SO}_{2}$ emissions. When the instrument accuracy was considered, the emissions from all fuels were indistinguishable. The baseline fuel figures are given in Appendix A.

The net stack temperature was measured during all tests. Analysis showed higher percentage SHO blends had higher stack temperatures. This was attributed to the larger volume of air required for proper combustion. The air flowed through the heat exchanger at higher velocities which prevented efficient heat exchange, which might indicate a need for change in heat exchanger design where SHO fuels are used. 


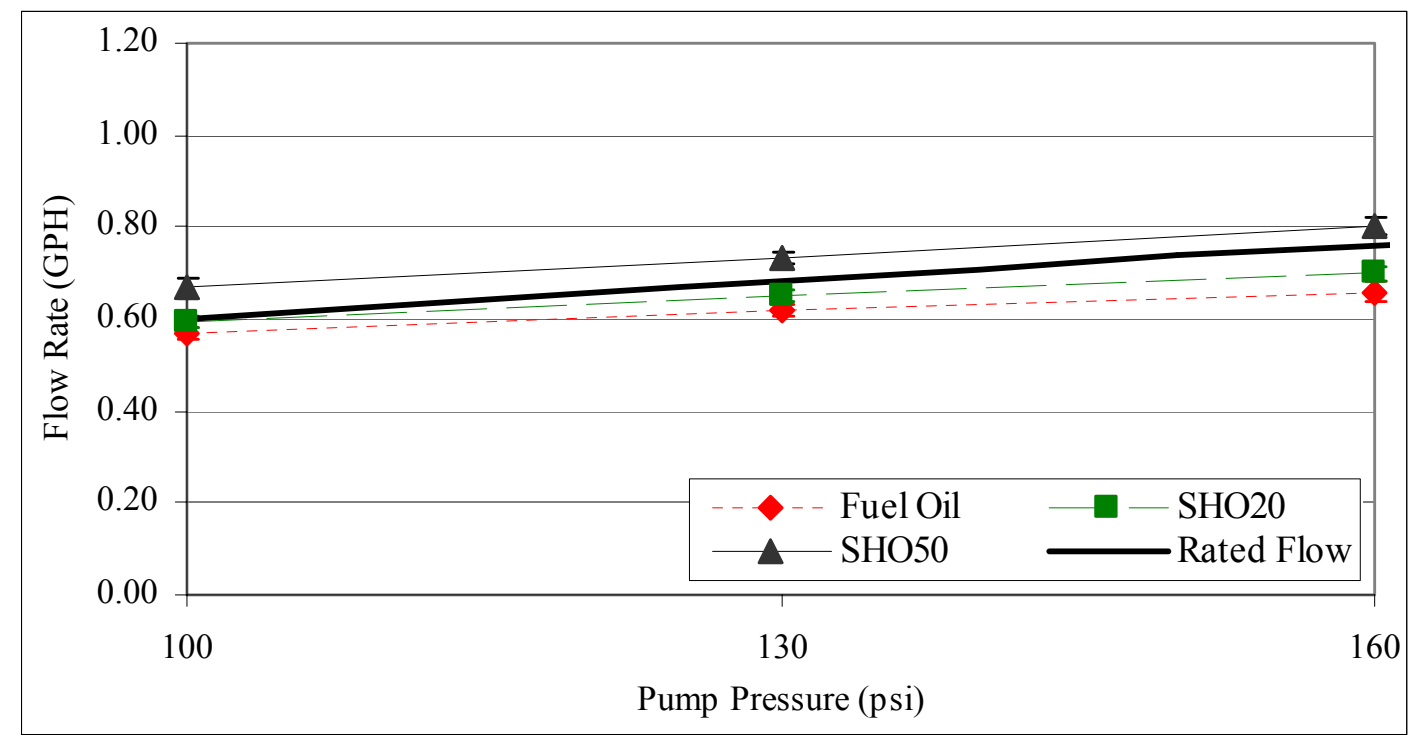

Figure 8 Fuel flow rates for the $0.60 \times 80^{\circ}$ nozzle

The volumetric fuel flow rate was measured for all furnace settings. A general upward trend for all samples was noted with an increase in pump pressure which was expected. Figure 8 shows SHO50 had higher flow rates at the $95 \%$ confidence interval for all furnace settings. This result was initially questioned but other researchers have reported increased flow rates with an increase in fuel viscosity (Litzke 2003).Conclusion

Analysis of temperature points, heat energy content, viscosity and laboratory tests indicated SHO20 (20\% degummed soybean oil and $80 \%$ petroleum fuel oil) to be the maximum recommended blend ratio. SHO blends with soybean oil fractions below the maximum value could potentially be used in unmodified residential furnaces/boilers as long as they are properly adjusted by an oilheat technician.

Future research involving several furnace and boiler types is recommended. Additional fuel blends which include petroleum fuel oil, degummed soybean oil and biodiesel should also be analyzed. This type of blend could potentially increase the renewable component ratio while providing performance and economic advantages.

\section{Acknowledgements}

Indiana Soybean Board, Indianapolis, IN

United Soybean Board, St. Louis, MO

Roger McDonald - Brookhaven National Laboratory, Long Island, NY

Thermopride - North Judson, IN 


\section{References}

Anonymous (1999). Energy \& Biomass Engineering. St. Joseph, MI, American Society of Agricultural Engineers.

Boone, L. P. (1952). The Petroleum Dictionary, University of Oklahoma Press.

Brewer, D. (2002). The Oilheat Industry Roadmap - Toward a Sustainable Energy Future. The 2002 National Oilheat Research Alliance Technology Symposium, Providence, RI, Brookhaven National Laboratory.

Erickson, D. R., E. H. Pryde, et al., Eds. (1980). Handbook of Soy Oil Processing and Utilization. St. Louis, American Soybean Association and the American Oil Chemists' Society.

Fernando, S. and M. Hanna (2001). "Comparison of Viscosity Characteristics of Soybean Oils with a Mineral Oil Two-Stroke Engine Lubricant." Transactions of the ASAE 44(6): 1403-1407.

Gunstone, F. D., Ed. (2002). Vegetable Oils in Food Technology: Composition, Properties and Uses. Boca Raton, FL, Blackwell.

Hedden, B., Ed. (2003). NORA Oilheat Technician's Manual, National Oilheat Research Alliance.

Hiler, E. A. and B. A. Stout, Eds. (1985). Biomass Energy A Monograph. College Station, Texas A\&M University Press.

Hui, Y. H., Ed. (1996). Edible Oil \& Fat Products: Processing Technology. Bailey's Industrial Oil \& Fat Products. New York, John Wiley \& Sons.

Krishna, C. R., R.J. McDonald (2003). The Green Fuel Option for the Oilheat Industry - Biofuel Research. The 2003 National Oilheat Research Alliance Technology Symposium, Boston, MA, Brookhaven National Laboratory.

Litzke, W. L., Robert Hedden (2003). National Oilheat Research Alliance Fuel Performance Research Update. The 2003 National Oilheat Research Alliance Technology Symposium, Boston, MA, Brookhaven National Laboratory.

Williams, A. (1989). Combustion of Liquid Fuel Sprays. London [England]; Boston, Butterworths. 


\section{Appendix A}

\begin{tabular}{|c|c|c|c|c|}
\hline Method & Test & Fuel Oil Results & SHO 20 Results & Units \\
\hline ASTM D2622 & Sulfur & 277 & 216 & $\mathrm{ppm}(\mathrm{Wt})$ \\
\hline ASTM D445 (IP 71S1) & Kinematic Viscosity at $37.8 \mathrm{C}, 100 \mathrm{~F}$ & 2.089 & 3.457 & cSt \\
\hline \multirow{2}{*}{ ASTM D5773 (IP 446) } & Cloud Point & -12.8 & -27 & ${ }^{\circ} \mathrm{C}$ \\
\hline & Cloud Point & 9 & -16.6 & ${ }^{\circ} \mathrm{F}$ \\
\hline \multirow{2}{*}{ ASTM D5949 } & Pour Point & -29 & -30 & ${ }^{\circ} \mathrm{C}$ \\
\hline & Pour Point & -20 & -22 & ${ }^{\circ} \mathrm{F}$ \\
\hline \multirow{2}{*}{ ASTM D6371 (IP 309) } & Cold Filter Plugging Point & -34 & -32.5 & ${ }^{\circ} \mathrm{C}$ \\
\hline & Cold Filter Plugging Point & -29.2 & -26.5 & ${ }^{\circ} \mathrm{F}$ \\
\hline \multirow{2}{*}{ ASTM D93 (IP34) Method A } & Corrected Flash Point & 68 & 71 & ${ }^{\circ} \mathrm{C}$ \\
\hline & Corrected Flash Point & 154 & 160 & ${ }^{\circ} \mathrm{F}$ \\
\hline
\end{tabular}


